Supporting Information

for

\title{
Efficient Photochemical Dihydrogen Generation Initiated by a Bimetallic Self-Quenching Mechanism
}

Matthew B. Chambers, Daniel A. Kurtz, Catherine L. Pitman, M. Kyle Brennaman and Alexander J. M. Miller*

Department of Chemistry, University of North Carolina at Chapel Hill, Chapel Hill, North Carolina 27599-3290, United States

ajmm@email.unc.edu 


\section{Supporting Information}

Table of Contents

I. Experimental Details $\quad$ S3

$\begin{array}{ll}\text { II. Synthetic Procedures } & \text { S7 }\end{array}$

III. Preliminary Kinetic Data in $\mathrm{H}_{2} \mathrm{O} \quad$ S9

IV. Isotopically Labelled Acid Photolyses of 1 Followed by ${ }^{1} \mathrm{H}$ NMR $\quad$ S10

V. Quantum Yield Determinations $\quad$ S16

$\begin{array}{lll}\text { VI. } & \Delta \mathrm{G}_{\mathrm{ST}} \text { Considerations } & \text { S22 }\end{array}$

VII. Steady State Photoluminescence Quenching S25

VIII. Time-Resolved Photoluminescence Quenching $\quad$ S27

$\begin{array}{ll}\text { IX. Electrochemical Results } & \text { S38 }\end{array}$

X. Thermochemical Evaluation of 1 * Reactivity Pathways $\quad$ S40

$\begin{array}{lll}\text { XI References } & \text { S43 }\end{array}$ 


\section{$\underline{\text { I. Experimental Details }}$ \\ General Considerations}

Manipulations were performed under the inert nitrogen atmosphere of a Schlenk line or a glovebox, except as noted. Glacial acetic acid $\left(\mathrm{CH}_{3} \mathrm{CO}_{2} \mathrm{H}\right)$ was thoroughly degassed by sparging nitrogen prior to storage under a nitrogen atmosphere within a glovebox. Organic solvents were dried and degassed with argon using a Pure Process Technology solvent system. $\mathrm{CD}_{3} \mathrm{CN}$ and acetic acid- $d_{4}\left(\mathrm{CD}_{3} \mathrm{CO}_{2} \mathrm{D}\right)$ were purchased from Cambridge Isotope Laboratories, Inc. $\mathrm{CD}_{3} \mathrm{CN}$ was degassed by three freeze-pump-thaw cycles before storage over $4-\AA$ molecular sieves. $\mathrm{CD}_{3} \mathrm{CO}_{2} \mathrm{D}$ was packaged in single-use sealed ampules and used as received. $\left[\mathrm{Cp} * \operatorname{Ir}(\mathrm{Cl})_{2}\right]_{2}$, $\left[\mathrm{Cp}^{*} \operatorname{Ir}(\mathrm{bpy}) \mathrm{Cl}\right][\mathrm{Cl}]$ and $\mathrm{Cp} * \operatorname{Ir}(\mathrm{bpy})$ were synthesized following established procedures. ${ }^{1,2}$ Tetrabutylammonium hexafluorophosphate $\left(\left[\mathrm{Bu}_{4} \mathrm{~N}\right]\left[\mathrm{PF}_{6}\right]\right)$ was twice-recrystallized from ethanol. Triethylammonium tetarfluoroborate $\left(\left[\mathrm{Et}_{3} \mathrm{NH}\right]\left[\mathrm{BF}_{4}\right]\right)$ was prepared through an anion exchange using commercially available triethylammonium chloride $\left(\left[\mathrm{Et}_{3} \mathrm{NH}\right][\mathrm{Cl}]\right)$, Sigma Aldrich $99 \%$, and silver tetrafluoroborate $\left(\mathrm{AgBF}_{4}\right)$, Sigma Aldrich $98 \%$ in acetonitrile. Characterization closely matched previous reports. ${ }^{3}$ The isotopically labeled triethylammonium- $d_{1}$ tetrafluoroborate $\left(\left[\mathrm{Et}_{3} \mathrm{ND}\right]\left[\mathrm{BF}_{4}\right]\right)$ was prepared in an analogous manner to the previously reported tributylammonium- $d_{1}$ tetrafluoroborate $\left(\left[\mathrm{Bu}_{3} \mathrm{ND}\right]\left[\mathrm{BF}_{4}\right]\right){ }^{4}$

${ }^{1} \mathrm{H}$ NMR spectra were recorded on 400 or $600 \mathrm{MHz}$ spectrometers at $25^{\circ} \mathrm{C}$. Chemical shifts are reported with respect to residual proteo solvent. Spectra were processed using the MestReNova software suite from Mestrelab Research S. L. UV-vis spectra were obtained with an Ocean Optics USB2000+ spectrometer with a DT-MINI-2GS deuterium/tungsten halogen light source controlled by Ocean View software.

\section{Steady State Photolysis Methods for ${ }^{1}$ H NMR Analysis}

Visible light photolyses were carried out using an Eagle Light $460 \mathrm{~nm}( \pm 13 \mathrm{~nm}$ at half-max intensity) LED lamp (500 lumens at $15 \mathrm{~W}$ ). All solutions and samples were prepared in a glovebox under an atmosphere of $\mathrm{N}_{2}$. Solutions of $[\mathrm{Cp} * \operatorname{Ir}(\mathrm{bpy}) \mathrm{H}]\left[\mathrm{PF}_{6}\right]$ were prepared in $\mathrm{CD}_{3} \mathrm{CN}$ with concentrations ranging between $1 \mathrm{mM}$ and $22 \mathrm{mM}$. All solutions included $100 \mathrm{mM}$ of $\mathrm{CD}_{3} \mathrm{CO}_{2} \mathrm{D}$ (or $100 \mathrm{mM}$ of $\left[\mathrm{NEt}_{3} \mathrm{D}\right]\left[\mathrm{BF}_{4}\right]$ ) as an acid source and $50 \mathrm{mM}$ of mesitylene as an internal integration standard. Photolysis samples were $0.5 \mathrm{~mL}$ in volume and prepared and sealed in a J-young tube prior to being removed from the glovebox. Photolyses were performed by irradiating the J-Young tube with a $460 \mathrm{~nm}$ LED lamp. Samples were positioned $50 \mathrm{~cm}$ in front of the light source with center of the sample being positioned in the center of the light beam.

After commencing photolysis, reaction progress was monitored periodically by ${ }^{1} \mathrm{H}$ NMR spectroscopy. For the first minute of irradiation time, data was collected every 15 seconds. Between 2 and 10 minutes of total irradiation time, spectra were collected every 1 minute. Between 10 and 20 minutes, spectra were collected every 5 minutes. One final spectrum was collected after 30 minutes of total irradiation time. For each measurement, approximately 7 minutes passed between the end of the photolysis and the data acquisition at which time the samples were shielded from light.

The integration of $\mathrm{H}_{2}$ versus $\mathrm{HD}$ was measured and converted to a concentration observed in solution upon comparison to the internal mesitylene standard. The concentration of $\mathrm{H}_{2}$ was corrected for para- $\mathrm{H}_{2}$ by applying a correction factor of 1.3 to the measured concentration of $\mathrm{H}_{2}{ }^{5}$ The concentration values are not corrected for diffusion of the gases out of solution. Refer to section IV for data and results. 


\section{Steady State Photolysis Methods for Quantum Yield Determination by UV-vis Analysis}

Quantum yields were determined using a 4-channel collimated high-power LED source from ThorLabs with a DC4100 driver for controllable light intensity through applied current. The LED source emits $443 \mathrm{~nm}$ light and unless otherwise noted was set to a constant current of 250 $\mathrm{mA}$. Samples were centered in the light beam positioned $8 \mathrm{~cm}$ in front of the source. All samples were prepared in a $1 \mathrm{~cm}$ path length quartz fluorescence cuvette purchase (Starna Cells) equipped with a screw cap and containing a total volume of $2 \mathrm{~mL}$. Iridium-containing samples were prepared and capped within an $\mathrm{N}_{2}$-filled glovebox. Upon removal from the glovebox, the screw cap was reinforced by thoroughly wrapping with parafilm. Photochemical reactions were monitored by UV-vis using an Ocean Optics USB2000+ spectrometer with a DT-MINI-2GS deuterium/tungsten halogen light source controlled by Ocean View software. For further details of data analysis, refer to section $\mathrm{V}$.

\section{Electrochemical Methods}

Cyclic voltammetry $(\mathrm{CV})$ measurements in $\mathrm{CH}_{3} \mathrm{CN}$ were performed in a nitrogen glovebox using either a Pine Instrument WaveNow or WaveDriver potentiostat controlled by Aftermath software. All potentials are reported with respect to the $\mathrm{Fc}^{+/ 0}$ internal standard. Experiments were carried out with glassy carbon working electrodes (polished with $0.05 \mu \mathrm{m}$ alumina powder), platinum wire counter electrodes, and a $\mathrm{Ag} / \mathrm{Ag}^{+}\left(0.200 \mathrm{M}\left[\mathrm{Bu}_{4} \mathrm{~N}\right]\left[\mathrm{PF}_{6}\right]\right.$ in $\left.\mathrm{CH}_{3} \mathrm{CN}\right)$ pseudoreference electrode in a small glass tube fitted with a Vycor frit. All potentials are reported relative to an internal $\mathrm{Cp}_{2} \mathrm{Fe}^{+/ 0}$ reference. Experiments were carried out in an undivided cell inside of an $\mathrm{N}_{2}$-filled glovebox. Solutions of $1 \mathrm{mM} 1$ were prepared in a $\mathrm{CH}_{3} \mathrm{CN}$ with $0.200 \mathrm{M}\left[\mathrm{Bu}_{4} \mathrm{~N}\right]\left[\mathrm{PF}_{6}\right]$ as a supporting electrolyte. Refer to section IX for data.

Chronoamperometry experiments of $\mathbf{1}$ in aqueous solutions followed a previously described experimental protocol. ${ }^{6}$ Experiments were performed in a divided H-cell with a threeelectrode configuration with a glassy carbon working electrode and platinum wire counter electrode were positioned on either side of the fine frit. $\mathrm{A} \mathrm{Ag} / \mathrm{AgCl}(3 \mathrm{M} \mathrm{NaCl})$ reference electrode was placed in the counter electrode compartment in a small glass tube fitted with a Vycor. Solutions were made by adjusting the $\mathrm{pH}$ of solutions of the appropriate concentration of sodium phosphate monobasic with $\mathrm{NaOH}$ and were thoroughly degassed by sparging with nitrogen for at least 15 min before beginning an experiment. All potentials are reported relative to NHE, with values obtained by adding $0.21 \mathrm{~V}$ to the experimentally observed potential vs $\mathrm{Ag} / \mathrm{AgCl}{ }^{7}$ For experiments under irradiation, the $460 \mathrm{~nm}$ LED lamp was placed directly below the glassy carbon electrode at a fixed distance. The potential was held between -0.4 and $-1.1 \mathrm{~V}$, based on the location of the reduction wave observed by cyclic voltammetry. At each potential, two traces were obtained in the light and in that dark with electrode polishing between each experiment. The ratio of the current in the light $\left(i_{\text {cat }}\right)$ to the current in the dark $\left(i_{\text {diff }}\right)$ was fit to the following equation:

$$
\frac{i_{c a t}}{i_{\text {diff }}}=\left(k_{o b s} t\right)^{1 / 2}\left[\pi^{1 / 2} \operatorname{erf}\left(\left(k_{o b s} t\right)^{1 / 2}\right)+\frac{\exp \left(-k_{o b s} t\right)}{\left(k_{o b s} t\right)^{1 / 2}}\right]
$$

where $k_{o b s}$ is the rate constant for the turnover-limiting chemical step and $t$ is time. ${ }^{8}$ The data was least-squares-fit between 5 and $10 \mathrm{~s}$ using the Excel solver function. At large applied overpotentials where electron transfer is fast and no longer rate limiting, $k_{o b s}$ reaches a limiting plateau that is dictated by the chemical steps of catalysis, $k_{\text {cat }}$. Observed rate constants were determined at a 
variety of applied potentials and $k_{\text {cat }}$ was found for three different concentrations of $1(0.25,0.50$ and $1.00 \mathrm{mM}){ }^{6}$ A plot of $k_{\text {cat }}$ Vs. [1] is shown Section III.

\section{Room Temperature Steady State Photoluminescence Methods}

Room temperature steady-state emission and excitation spectra were recorded on a Photon Technology, Inc. Quantamaster 4SE-NIR5 spectrometer PC-controlled by FelixX32 software Excitation light was provided by a $75 \mathrm{~W}$ Xenon light source coupled to a single monochromator outfitted with a $1200 \mathrm{~L} / \mathrm{mm}$ grating blazed at $400 \mathrm{~nm}$. A $300 \mathrm{~nm}$ long pass filter was placed before the sample to prevent deep UV excitation from a second order grating effect. Emission was collected at a right angle relative to excitation, focused into a single monochromator (grating blazed at 500nm with $1200 \mathrm{~L} / \mathrm{mm}$ ) and detected by a Hamamatsu R928P photomultiplier tube used in single photon counting mode. Slit widths for both emission and excitation monochromators were fixed at $0.5 \mathrm{~mm}$ for all experiments. All spectra were corrected for system response. Refer to section VII for results.

\section{K Steady State Photoluminescence Methods}

Low temperature steady state emission spectra (600-950 nm, every $1 \mathrm{~nm}, 0.2 \mathrm{~s}$ integration time, three averages) were collected at $77 \mathrm{~K}$ by inserting the NMR tube/liquid nitrogen coldfinger dewar into an Edinburgh FLS-920 emission spectrophotometer equipped with a thermoelectrically cooled $\left(-20^{\circ} \mathrm{C}\right)$ photomultiplier tube (R2658P, Hamamatsu). Visible excitation was provided by a $450 \mathrm{~W}$ Xe source focused into a monochromator. Spectral bandwidth for both emission and excitation monochromators was fixed at $10 \mathrm{~nm}$. A $320 \mathrm{~nm}$ long-pass filter was placed in the path of the excitation beam just before the sample to avoid UV photoexcitation arising from secondorder grating effects. A $570 \mathrm{~nm}$ long-pass filter was placed between the sample and the emission monochromator to avoid stray light and second-order grating effects from visible excitation light scattered from the curved surfaces of the glassware. Resulting spectra were corrected for the transmission of both the $570 \mathrm{~nm}$ long-pass filter and the spectral response of the system. Spectral correction factors were collected in a separate experiment using a NIST-traceable standard tungsten lamp. Samples were prepared using a 5:4 mixture of propionitrile:butyronitrile as a solvent. A $2 \mathrm{mM}$ solution of 1 was prepared inside an $\mathrm{N}_{2}$-filled glovebox. The solution was transferred to a J-Young NMR tube. The J-Young tube was placed within the cold finger which was mounted inside the spectrophotometer. Multiple positions of the J-Young tube were sampled in order to achieve the optimal signal to noise ratio.

Spectral fitting of the emission data was performed to estimate the value of the energy gap between the ground state and the triplet excited state for $1, \Delta G_{\mathrm{ST}}$ or $\mathrm{E}_{00}$. The fitting requires a value of the separation of vibrational energy levels $\left(\hbar \omega_{\mathrm{M}}\right)$. Corrected emission intensities were converted to units of quanta per second by multiplication by the square of the emission wavelength in nanometers. ${ }^{9}$ Following conversion of the $\mathrm{x}$-axis from wavelength to wavenumber, emission spectral fitting was performed by using the single-average-mode, Franck-Condon expression shown below ${ }^{10-13}$ :

$$
I(\tilde{v})=\sum_{v_{M}=0}^{\infty}\left\{\left(\frac{E_{0}-v_{M} \hbar \omega}{E_{0}}\right)^{3}\left(\frac{S_{M}^{v_{M}}}{v_{M} !}\right) \times \exp \left[-4 \ln (2)\left(\frac{\tilde{v}-E_{0}+v_{M} \hbar \omega}{\Delta \tilde{v}_{0,1 / 2}}\right)^{2}\right]\right\}
$$


$E_{0}$ is defined as the difference between the lowest-energy vibrational level of the ${ }^{3} \mathrm{MLCT}$ excited state and the lowest-energy vibrational level of the ground state. The full-width-at-halfmaximum (FWHM) of the gaussian-broadened, $0-0$ vibronic component is $\Delta \tilde{v}_{0,1 / 2}$. The quantum vibrational energy spacing of the averaged, single-acceptor mode of medium frequency is denoted by $\hbar \omega_{\mathrm{M}}$. The average medium-frequency, electron-vibrational coupling constant, $\mathrm{S}_{\mathrm{M}}$, is also known as the Huang-Rhys factor. Fits were performed in MatLab (The MathWorks, Inc.; version $\mathrm{R} 2014 \mathrm{~b}$ ) by fixing $\hbar \omega_{\mathrm{M}}$ from $1100-1500 \mathrm{~cm}^{-1}$ while allowing parameters $E_{0}, \Delta \tilde{v}_{0,1 / 2}$, and $\mathrm{S}_{\mathrm{M}}$ to become iteratively optimized by use of a trust-region-reflective, least squares algorithm using code based on eq. 1 with 11 vibrational levels $\left(v_{\mathrm{M}}=0 \rightarrow 10\right)$. A range of starting values for the variable parameters were explored to ensure convergence to a global minimum. Refer to section VI for results.

\section{Time-Resolved Photoluminescence Methods}

Time resolved photoluminescence experiments were performed using a custom-built laser flash photolysis system. Laser excitation (5-7 ns FWHM, $10 \mathrm{~Hz}$, Q-switched) was provided by the third harmonic of a Nd:YAG laser (Spectra-Physics, Inc., model Quanta-Ray LAB-170-10) that pumped an OPO (basiScan, GWU Lasertechnik) to access tunable excitation (415-800 nm). Laser power at the sample cuvette was attenuated by the use of a half waveplate (WPMH10M-355, ThorLabs) and polarizer (GL10-A, ThorLabs). A glass window was used to deflect a small portion of excitation beam to a Si diode detector (DET10A, ThorLabs), triggering the oscilloscope to start data collection. Timing of the laser was controlled by a digital delay generator (9514+ Pulse Generator, Quantum Composers).

Single wavelength time resolved emission data (monitored at $708 \mathrm{~nm}$ ) was obtained using a double slit monochromator (Spectral Products CM112) outfitted with a Hamamatsu R928 photomultiplier tube (PMT). The signal intensity was attenuated with a neutral density filter, and scattered excitation light was filtered with a color filter wheel containing various long pass and short pass filters. The signal was amplified by a $200 \mathrm{MHz}$ wideband voltage amplifier (DHPVA200, Electro Optical Components) and processed using a digitizer (CompuScope 12502, GaGeScope) controlled by custom software (MATLAB). A dark current (detection without laser excitation) was subtracted from the raw luminescence data, and further analyzed and fit to a monoexponential decay using OriginPro 8 software.

Samples were prepared in a $\mathrm{N}_{2}$-filled glovebox. Custom made quartz cuvettes with a Teflon sealed plug were used to maintain an oxygen-free atmosphere throughout data collection. Unless otherwise stated, a $100 \mathrm{mM}\left[\mathrm{Bu}_{4} \mathrm{~N}\right]\left[\mathrm{PF}_{6}\right]$ solution in $\mathrm{CH}_{3} \mathrm{CN}$ was used as the solvent with and without acid present. For studies in which the concentration of $\mathbf{1}$ or 1-D was varied, a stock solution of about $1 \mathrm{mM}$ of the iridium complex was prepared. The stock solution was sequentially diluted, with the lowest concentration nearing $0.1 \mathrm{mM}$. The concentration of each sample was verified prior to data acquisition by UV-vis spectroscopy. Refer to section VIII for results. 


\section{Synthetic Procedures}

$\left[C p^{*} \operatorname{Ir}(\right.$ bpy $\left.) H\right]\left[P F_{6}\right](\mathbf{1})$

Procedure modified from published synthesis of $[\mathrm{Cp} * \operatorname{Ir}(\mathrm{bpy}) \mathrm{H}][\mathrm{OTf}] .{ }^{14}$ A $3 \mathrm{M}$ formic acid solution was prepared by adding $5.8 \mathrm{~mL} 98 \%$ formic acid to $50 \mathrm{~mL}$ of water. The solution was adjusted to $\mathrm{pH} 5$ ( $\mathrm{pH}$ electrode meter) using potassium hydroxide. The formic acid solution was sparged in a nitrogen-filled glovebox. Addition of $10 \mathrm{~mL}$ of $3 \mathrm{M}$ formic acid at $\mathrm{pH} 5$ to $200 \mathrm{mg}$ $(0.361 \mathrm{mmol})[\mathrm{Cp} * \operatorname{Ir}(\mathrm{bpy}) \mathrm{Cl}][\mathrm{Cl}]$ in a $20 \mathrm{~mL}$ scintillation vial produced a yellow solution that was protected from light and stirred for $4 \mathrm{~h}$. After the first hour, the reaction vessel cap was vented to release any $\mathrm{CO}_{2}$ generated during the reaction. The cap was then replaced and the solution was stirred for and addition $3 \mathrm{~h}$. The resulting yellow solution was filter through celite and excess $\mathrm{KPF}_{6}$ (500 $\mathrm{mg}, 2.86 \mathrm{mmol}$ ) was added to afford a yellow precipitate. The suspension was filtered through fresh celite with a yellow powder collected on the celite. The celite was washed with water $(3 \times 2$ $\mathrm{mL})$ followed by diethyl ether $(3 \times 2 \mathrm{~mL})$. Acetonitrile $(10 \mathrm{~mL})$ was then passed through the celite, dissolving the yellow powder and afforded a golden yellow solution. The solution was evaporated under vacuum to yield pure 1. Spectroscopic data closely matched the previously reported synthesis for $1 .{ }^{15} \mathrm{H}$ NMR $\left(\mathrm{CD}_{3} \mathrm{CN}\right): 8.89(\mathrm{~d}, J=5.7 \mathrm{~Hz}, 2 \mathrm{H}), 8.38(\mathrm{td}, J=7.9,1.4 \mathrm{~Hz}, 2 \mathrm{H}), 8.07$ $(\mathrm{t}, J=7.9 \mathrm{~Hz}, 2 \mathrm{H}), 7.59(\mathrm{ddd} J=7.3,5.7,1.4 \mathrm{~Hz}, 2 \mathrm{H}), 1.83(\mathrm{~s}, 15 \mathrm{H}),-11.57(\mathrm{~s}, 1 \mathrm{H})$.

\section{$[C p * \operatorname{Ir}($ bpy $)(D)]\left[P F_{6}\right](\mathbf{1}-\mathbf{D})$}

A $20 \mathrm{ml}$ scintillation vial was charged with $50 \mathrm{mg}(0.10 \mathrm{mmol})$ of $\mathrm{Cp} * \operatorname{Ir}(\mathrm{bpy})$. Addition of $10 \mathrm{~mL}$ of $\mathrm{Et}_{2} \mathrm{O}$ to $\mathrm{Cp}^{*} \operatorname{Ir}(\mathrm{bpy})$ afforded a dark purple solution. While stirring, $0.5 \mathrm{~mL}$ (8.2 mmol) of $\mathrm{CD}_{3} \mathrm{CO}_{2} \mathrm{D}$ was pipetted into the vial dropwise. The mixture quickly took on a yellow appearance and formed a golden yellow precipitate. The mixture was filtered through celite and the golden yellow solid remaining on the celite was washed $3 \times 2 \mathrm{ml}$ with $\mathrm{Et}_{2} \mathrm{O}$. The solid was redissolved in $\mathrm{D}_{2} \mathrm{O}$ by washing $3 \times 4 \mathrm{~mL}$ of $\mathrm{D}_{2} \mathrm{O}$ through the celite and collecting the resulting yellow solution in a $20 \mathrm{~mL}$ scintillation vial. To the yellow solution was added excess $\mathrm{KPF}_{6}\left(200 \mathrm{mg}, 1.1 \mathrm{mmol}^{2}\right.$ to afford the product as a golden yellow precipitate. The golden yellow product was collected by filtration on celite and a minimal amount of $\mathrm{CH}_{3} \mathrm{CN}$ was passed through the celite to redissolve the product as a yellow solution. The solution was dried in vacuo to yield the product in $61 \%$ yield (39 mg). By ${ }^{1} \mathrm{H}$ NMR spectroscopy, the iridium hydride was $88 \%$ isotopically labeled. ${ }^{1} \mathrm{H}$ NMR $\left(\mathrm{CD}_{3} \mathrm{CN}\right): 8.89(\mathrm{~d}, J=5.7 \mathrm{~Hz}, 2 \mathrm{H}), 8.38(\mathrm{td}, J=7.9,1.4 \mathrm{~Hz}, 2 \mathrm{H}), 8.07$ (t, $\left.J=7.9 \mathrm{~Hz}, 2 \mathrm{H}\right), 7.59$ (ddd $J=7.3,5.7,1.4 \mathrm{~Hz}, 2 \mathrm{H}), 1.83(\mathrm{~s}, 15 \mathrm{H}),-11.57(\mathrm{~s}, 0.12 \mathrm{H})$ 


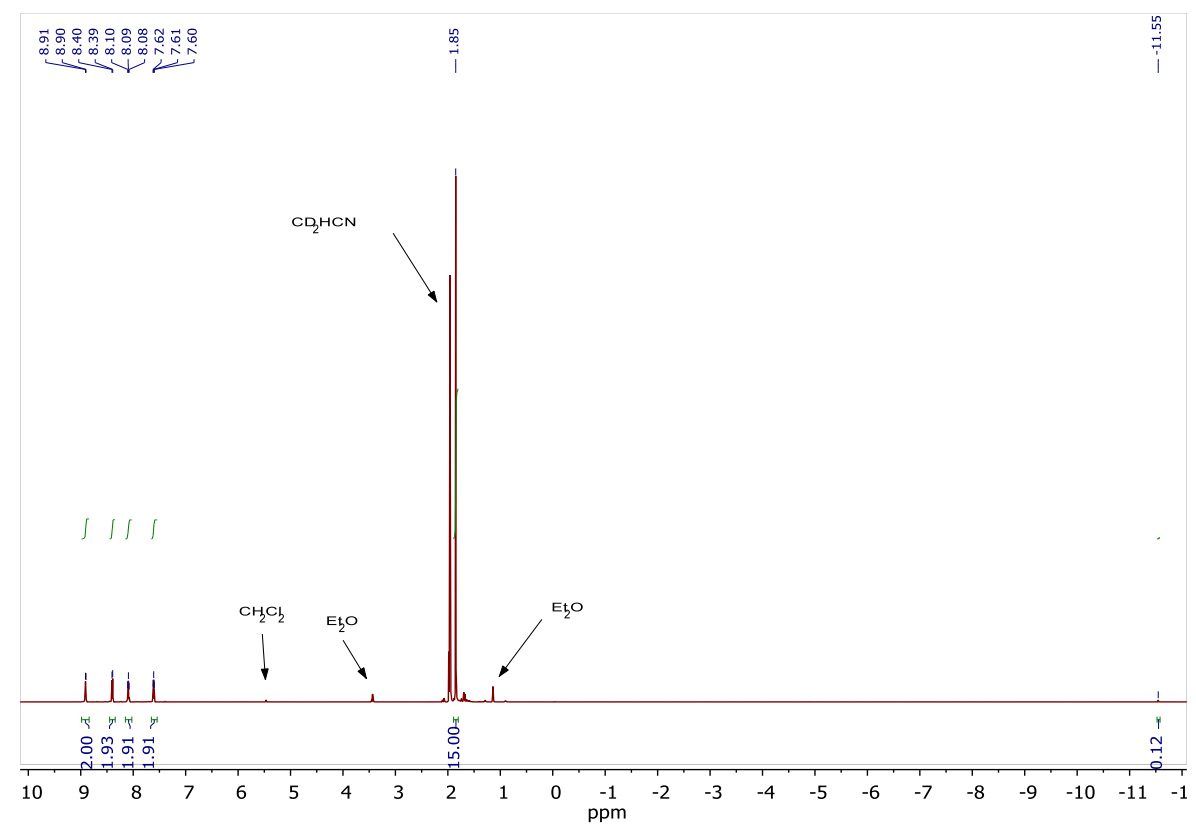

Figure S1. ${ }^{1} \mathrm{H}$ NMR spectrum of $\left.[\mathrm{Cp} * \mathrm{Ir}(\mathrm{bpy}) \mathrm{D})\right]\left[\mathrm{PF}_{6}\right]$ in $\mathrm{CD}_{3} \mathrm{CN}$ at room temperature. Hydride resonance at -11.55 integrated to approximately $88 \%$ deuterium labelling. 


\section{Preliminary Kinetic Data in $\mathrm{H}_{2} \mathrm{O}$}

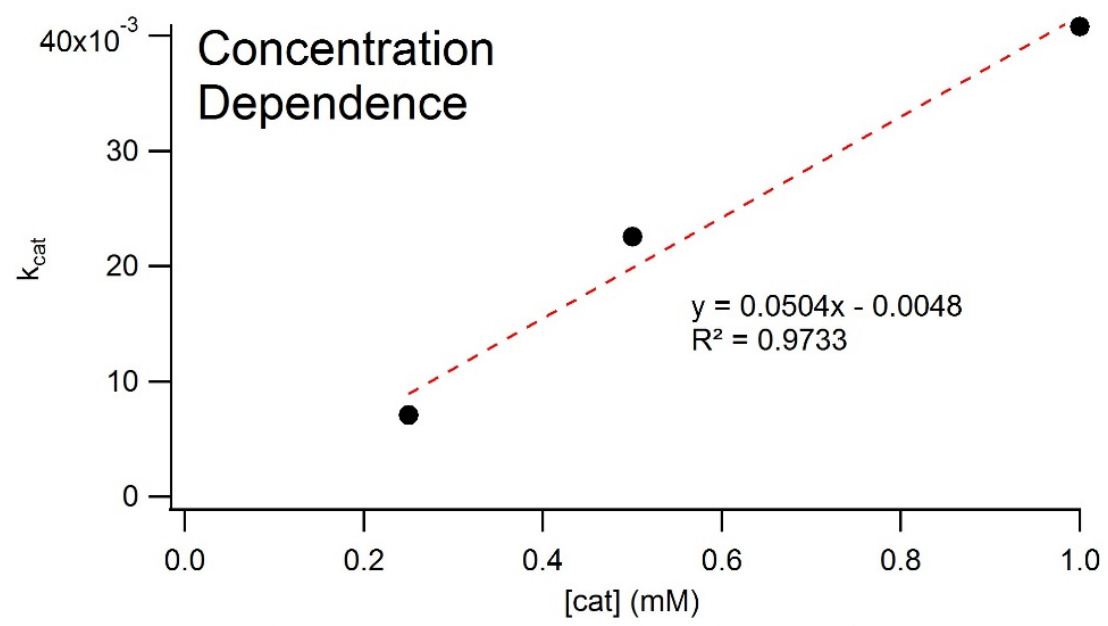

Figure S2. Observed rate constants for the photoelectrocatalytic generation of $\mathrm{H}_{2}$ by catalyst $\mathbf{1}$ in an aqueous environment ( $\mathrm{pH} 70.1 \mathrm{M}$ sodium phosphate) under illumination (460 nm LED) at concentrations of 1 between 0.25 $1.00 \mathrm{mM}$. The correlation between rate constant and concentration suggests the process is not simply first order in 1 . 


\section{Isotopically Labelled Acid Photolyses of 1 Followed by ${ }^{1} \mathrm{H}$ NMR Spectroscopy}

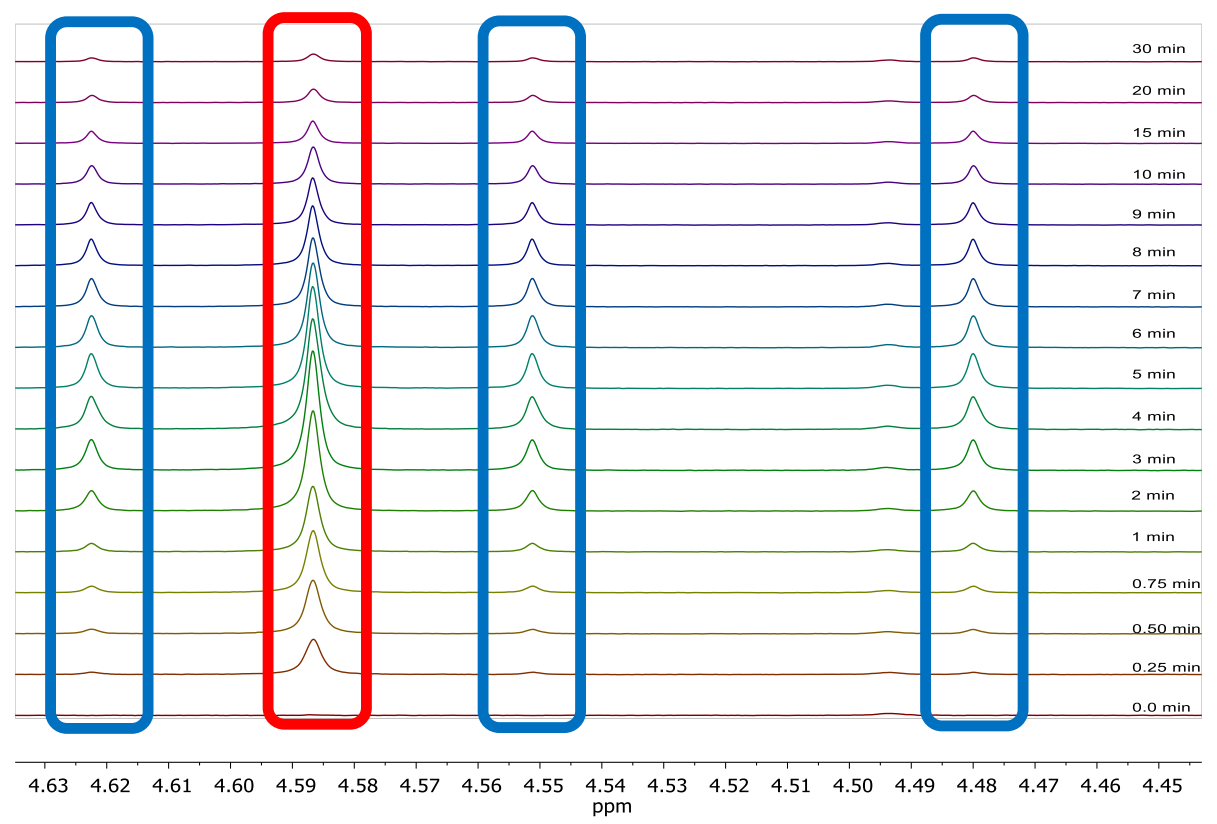

Figure S3. Representative ${ }^{1} \mathrm{H}$ NMR spectra showing the evolution of the $\mathrm{H}_{2}$ (red) and $\mathrm{HD}$ (blue) signals upon irradiation with $460 \mathrm{~nm}$ light of solutions $[\mathrm{Cp} * \operatorname{Ir}(\mathrm{bpy}) \mathrm{H}]\left[\mathrm{PF}_{6}\right]$ in $\mathrm{CD}_{3} \mathrm{CN}$ in the presence of $100 \mathrm{mM} \mathrm{CD}_{3} \mathrm{CO}_{2} \mathrm{D}$ and $50 \mathrm{mM}$ mesitylene for a given total irradiation time. Data presented if for sample of $[\mathrm{Cp} * \operatorname{Ir}(\mathrm{bpy}) \mathrm{H}]\left[\mathrm{PF}_{6}\right]$ with an initial concentration of $21.4 \mathrm{mM}$.

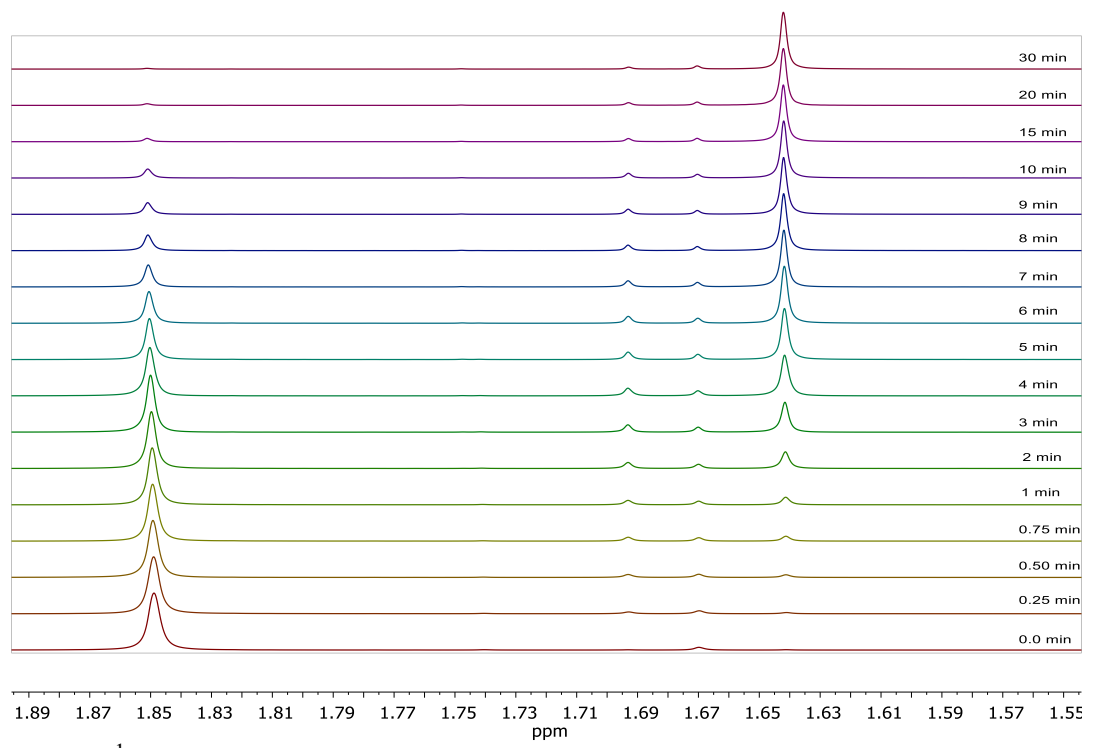

Figure S4. Representative ${ }^{1} \mathrm{H}$ NMR spectra showing the evolution of the $\mathrm{Cp}^{*}$ signals upon irradiation with $460 \mathrm{~nm}$ light of solutions $[\mathrm{Cp} * \operatorname{Ir}(\mathrm{bpy}) \mathrm{H}]\left[\mathrm{PF}_{6}\right]$ in $\mathrm{CD}_{3} \mathrm{CN}$ in the presence of $100 \mathrm{mM} \mathrm{CD}_{3} \mathrm{CO}_{2} \mathrm{D}$ and $50 \mathrm{mM}$ mesitylene. Data presented for sample of $[\mathrm{Cp} * \operatorname{Ir}(\mathrm{bpy}) \mathrm{H}]\left[\mathrm{PF}_{6}\right]$ with an initial concentration of $21.4 \mathrm{mM}$. Signals at $\delta 1.85,1.69$ and 1.64 correspond to $[\mathrm{Cp} * \operatorname{Ir}(\mathrm{bpy}) \mathrm{H}]\left[\mathrm{PF}_{6}\right],\left[\mathrm{Cp} * \operatorname{Ir}(\mathrm{bpy})\left(\mathrm{NCCD}_{3}\right)\right]\left[\mathrm{PF}_{6}\right],[\mathrm{Cp} * \operatorname{Ir}(\mathrm{bpy})(\mathrm{OAc})]\left[\mathrm{PF}_{6}\right]$ respectively. A trace amount of $[\mathrm{Cp} * \mathrm{Ir}(\mathrm{bpy}) \mathrm{Cl}] \mathrm{Cl}$ is observed at $\delta 1.67$ and does not change throughout the experiment. 


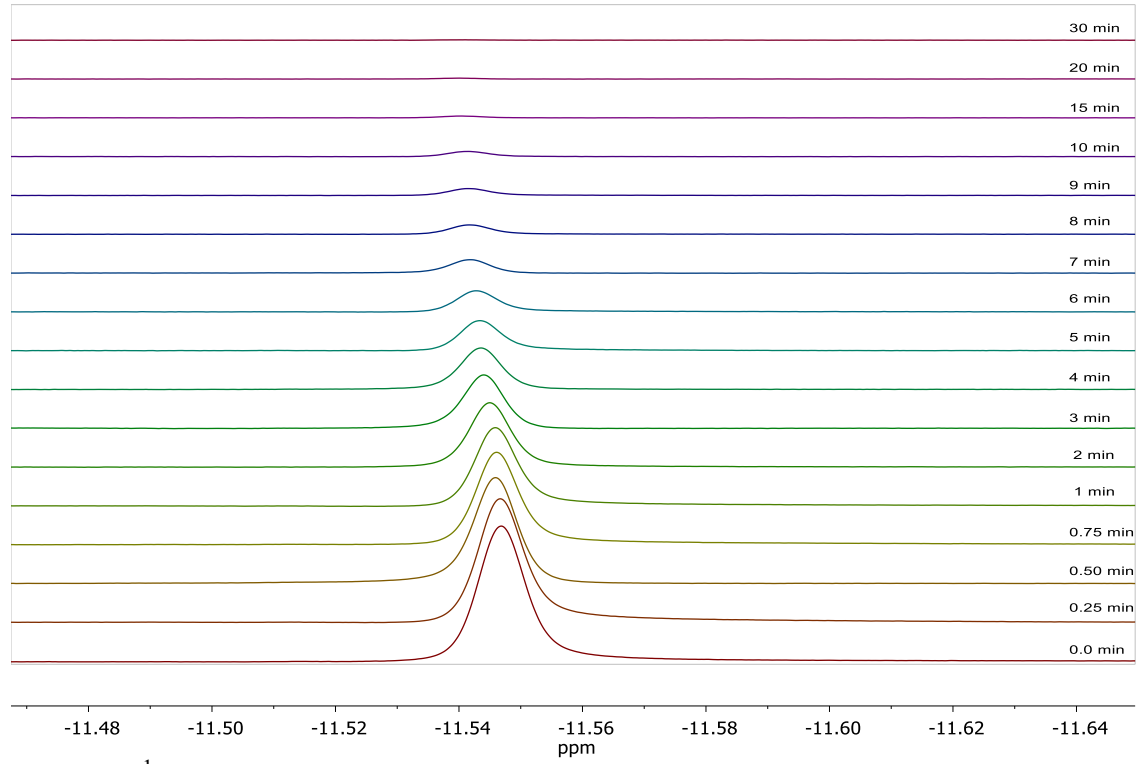

Figure S5. Representative ${ }^{1} \mathrm{H}$ NMR spectra showing the evolution of the $\mathrm{Ir}-\mathrm{H}$ resonance upon irradiation with 460 $\mathrm{nm}$ light of solutions [Cp*Ir(bpy)H] $\left[\mathrm{PF}_{6}\right]$ in $\mathrm{CD}_{3} \mathrm{CN}$ in the presence of $100 \mathrm{mM} \mathrm{CD}_{3} \mathrm{CO}_{2} \mathrm{D}$ and $50 \mathrm{mM}$ mesitylene. Data presented for sample of $[\mathrm{Cp} * \operatorname{Ir}(\mathrm{bpy}) \mathrm{H}]\left[\mathrm{PF}_{6}\right]$ with an initial concentration of $21.4 \mathrm{mM}$.
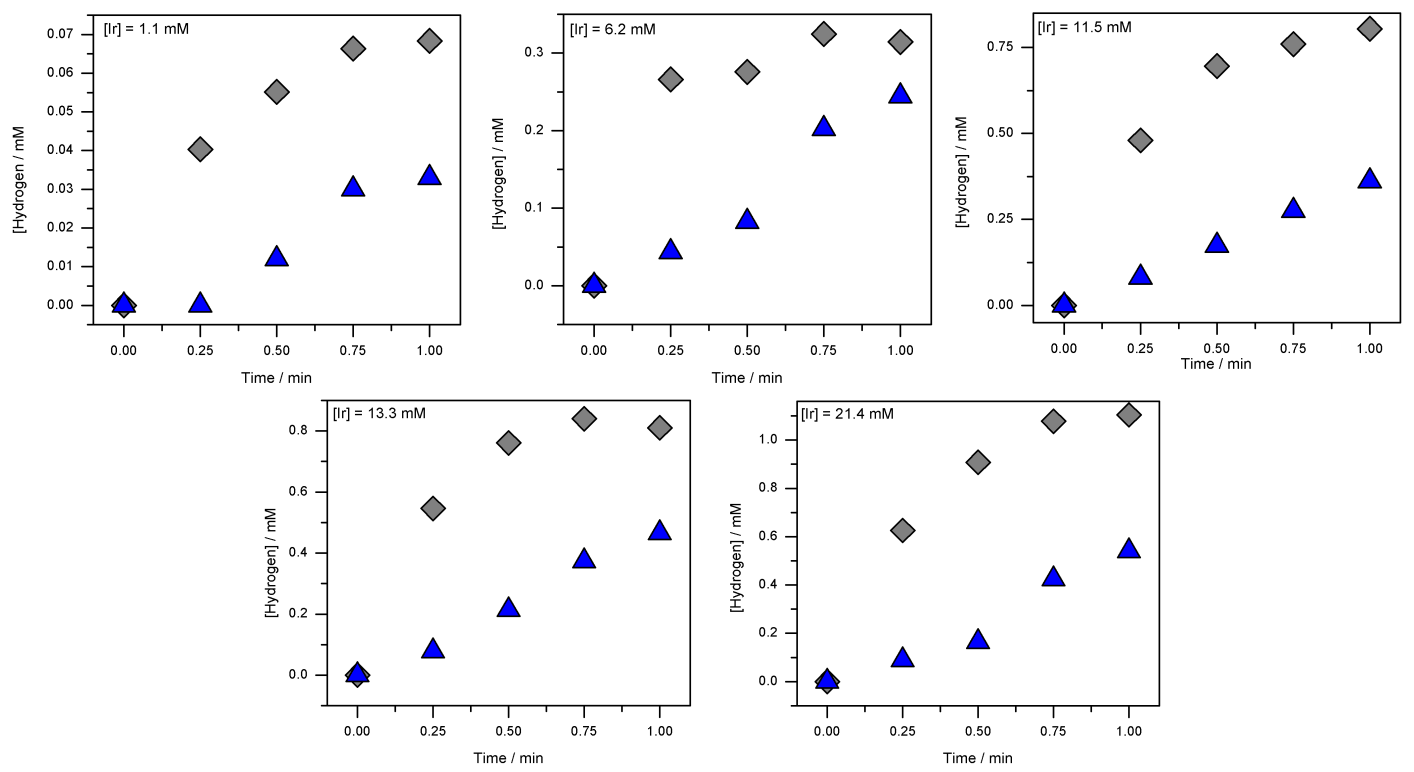

Figure S6. Production of $\mathrm{H}_{2}(\diamond)$ versus $\mathrm{HD}(\boldsymbol{\Delta})$ upon irradiation with $460 \mathrm{~nm}$ light of solutions [Cp* $\left.\operatorname{Ir}(\mathrm{bpy}) \mathrm{H}\right]\left[\mathrm{PF}_{6}\right]$ in $\mathrm{CD}_{3} \mathrm{CN}$ at various concentrations in the presence of $100 \mathrm{mM} \mathrm{CD}_{3} \mathrm{CO}_{2} \mathrm{D}$ and $50 \mathrm{mM}$ mesitylene in the first $1 \mathrm{~min}$. Concentrations of hydrogen determined by ${ }^{1} \mathrm{H}$ NMR spectroscopy and are not corrected for diffusion out of solution. Concentration of $\mathrm{H}_{2}$ is corrected for para- $\mathrm{H}_{2}$ by multiplying empirical concentration of $\mathrm{H}_{2}$ by a factor of 1.3 . 


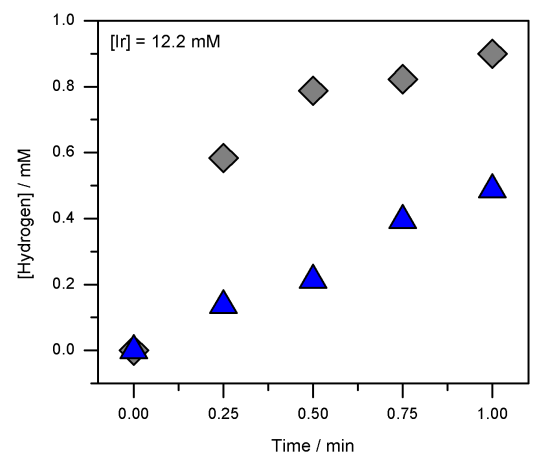

Figure S7. Production of $\mathrm{H}_{2}(\diamond)$ versus $\mathrm{HD}(\boldsymbol{\Delta})$ upon irradiation with $460 \mathrm{~nm}$ light of $12.2 \mathrm{mM}[\mathrm{Cp} * \operatorname{Ir}(\mathrm{bpy}) \mathrm{H}]\left[\mathrm{PF}_{6}\right]$ in $\mathrm{CD}_{3} \mathrm{CN}$ in the presence of $100 \mathrm{mM}\left[\mathrm{Et}_{3} \mathrm{ND}\right]\left[\mathrm{BF}_{4}\right] 50 \mathrm{mM}$ mesitylene over the first 1 min. Concentrations of hydrogen determined by ${ }^{1} \mathrm{H}$ NMR spectroscopy and are not corrected for diffusion out of solution. Concentration of $\mathrm{H}_{2}$ is corrected for para $-\mathrm{H}_{2}$ by multiplying empirical concentration of $\mathrm{H}_{2}$ by a factor of 1.3 .
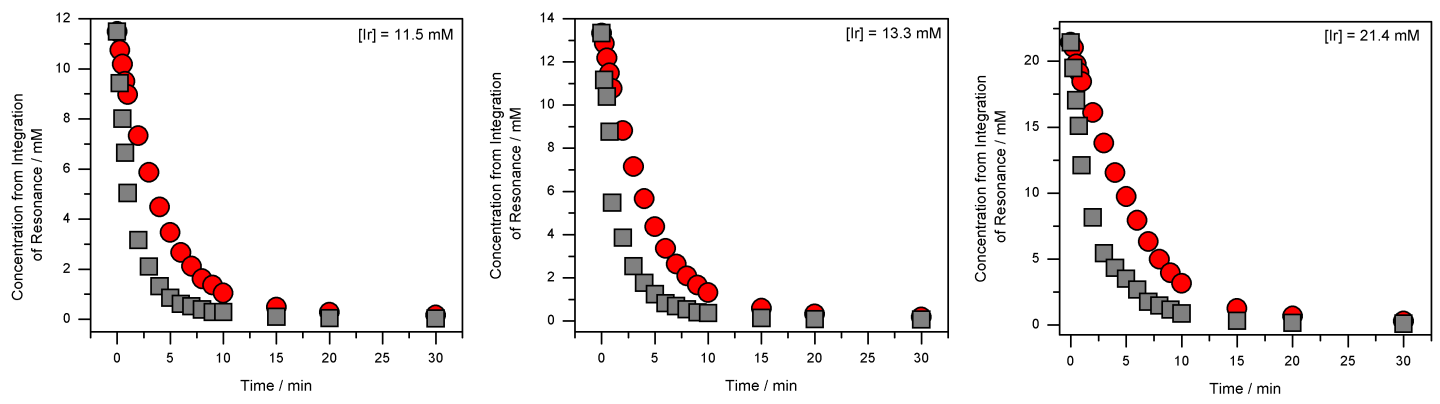

Figure S8. Decay of ${ }^{1} \mathrm{H}$ NMR resonance corresponding to equivalents of $\mathrm{Cp}^{*}(O)$ and the hydride $(\square)$ for $[\mathrm{Cp} * \operatorname{Ir}($ bpy $) \mathrm{H}]\left[\mathrm{PF}_{6}\right]$ upon irradiation with $460 \mathrm{~nm}$ light in $\mathrm{CD}_{3} \mathrm{CN}$ at various concentrations in the presence of 100 $\mathrm{mM} \mathrm{CD}_{3} \mathrm{CO}_{2} \mathrm{D}$ and $50 \mathrm{mM}$ mesitylene. Lower concentrations of $\left[\mathrm{Cp}^{*} \operatorname{Ir}(\mathrm{bpy}) \mathrm{H}\right]\left[\mathrm{PF}_{6}\right]$ were omitted due to difficulties in quantifying the broad and weak Ir-H resonance signal.

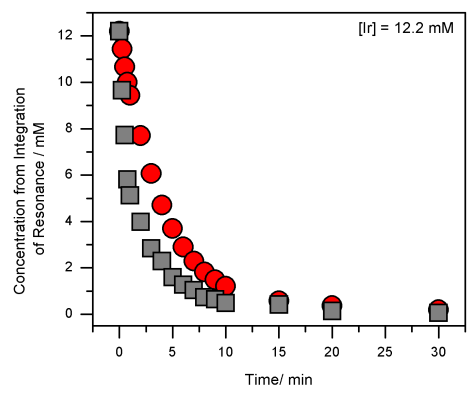

Figure S9. Decay of ${ }^{1} \mathrm{H}$ NMR resonance corresponding to equivalents of $\mathrm{Cp} *(\bigcirc)$ and the hydride $(\square)$ for a solution of $12.2 \mathrm{mM}[\mathrm{Cp} * \operatorname{Ir}(\mathrm{bpy}) \mathrm{H}]\left[\mathrm{PF}_{6}\right]$ in $\mathrm{CD}_{3} \mathrm{CN}$ upon irradiation with $460 \mathrm{~nm}$ light in the presence of $100 \mathrm{mM}$ $\left[\mathrm{NEt}_{3} \mathrm{D}\right]\left[\mathrm{BF}_{4}\right]$ and $50 \mathrm{mM}$ mesitylene. 


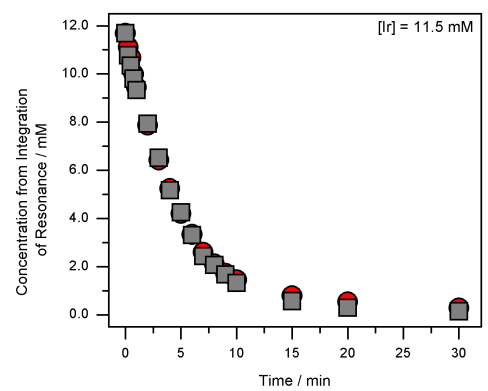

Figure S10. Decay of ${ }^{1} \mathrm{H}$ NMR resonance corresponding to equivalents of $\mathrm{Cp} *(\bigcirc)$ and the hydride $(\square)$ for a solution of $11.6 \mathrm{mM}[\mathrm{Cp} * \operatorname{Ir}(\mathrm{bpy}) \mathrm{H}]\left[\mathrm{PF}_{6}\right]$ in $\mathrm{CD}_{3} \mathrm{CN}$ upon irradiation with $460 \mathrm{~nm}$ light in the presence of $100 \mathrm{mM} \mathrm{CH}_{3} \mathrm{CO}_{2} \mathrm{H}$ and $50 \mathrm{mM}$ mesitylene. No difference in signal decay is observed. Initial rates analysis affords a rate of decay of 2.4 $\mathrm{mM} \min ^{-1}$.

Table S1. Initial rates of decay monitored by ${ }^{1} \mathrm{H}$ NMR spectroscopy for equivalents of $\mathrm{Cp}$ * and the $\mathrm{Ir}-\mathrm{H}$ upon irradiation with $460 \mathrm{~nm}$ light of solutions $[\mathrm{Cp} * \operatorname{Ir}(\mathrm{bpy}) \mathrm{H}]\left[\mathrm{PF}_{6}\right]$ in $\mathrm{CD}_{3} \mathrm{CN}$ at various concentrations in the presence of $100 \mathrm{mM} \mathrm{CD}_{3} \mathrm{CO}_{2} \mathrm{D}$ and $50 \mathrm{mM}$ mesitylene

\begin{tabular}{|c|c|c|c|}
\hline$[\mathbf{C p} * \mathbf{I r}(\mathbf{b p y}) \mathbf{H}]^{+}$ & Rate of $\mathbf{C p}^{*}$ decay & Rate of Hydride Decay & $\begin{array}{c}\text { Ratio of Hydride Decay to } \\
\text { Cp*Decay }\end{array}$ \\
\hline $11.5 \mathrm{mM}$ & $2.5 \mathrm{mM} \mathrm{min}^{-1}$ & $5.5 \mathrm{mM} \mathrm{min}^{-1}$ & 2.2 \\
\hline $12.2 \mathrm{mM}^{a}$ & $2.7 \mathrm{mM} \mathrm{min}^{-1 a}$ & $7.0 \mathrm{mM} \mathrm{min}^{-1 a}$ & $2.6^{a}$ \\
\hline $13.3 \mathrm{mM}$ & $2.6 \mathrm{mM} \mathrm{min}^{-1}$ & $4.8 \mathrm{mM} \mathrm{min}^{-1}$ & 1.8 \\
\hline $21.4 \mathrm{mM}$ & $2.7 \mathrm{mM} \mathrm{min}^{-1}$ & $6.1 \mathrm{mM} \mathrm{min}^{-1}$ & 2.3 \\
\hline
\end{tabular}

${ }^{a} 100 \mathrm{mM} \mathrm{CH}_{3} \mathrm{CO}_{2} \mathrm{H}$ replaced by $100 \mathrm{mM}$ of $\left[\mathrm{Et}_{3} \mathrm{ND}\right]\left[\mathrm{BF}_{4}\right]$ as an acid source. 


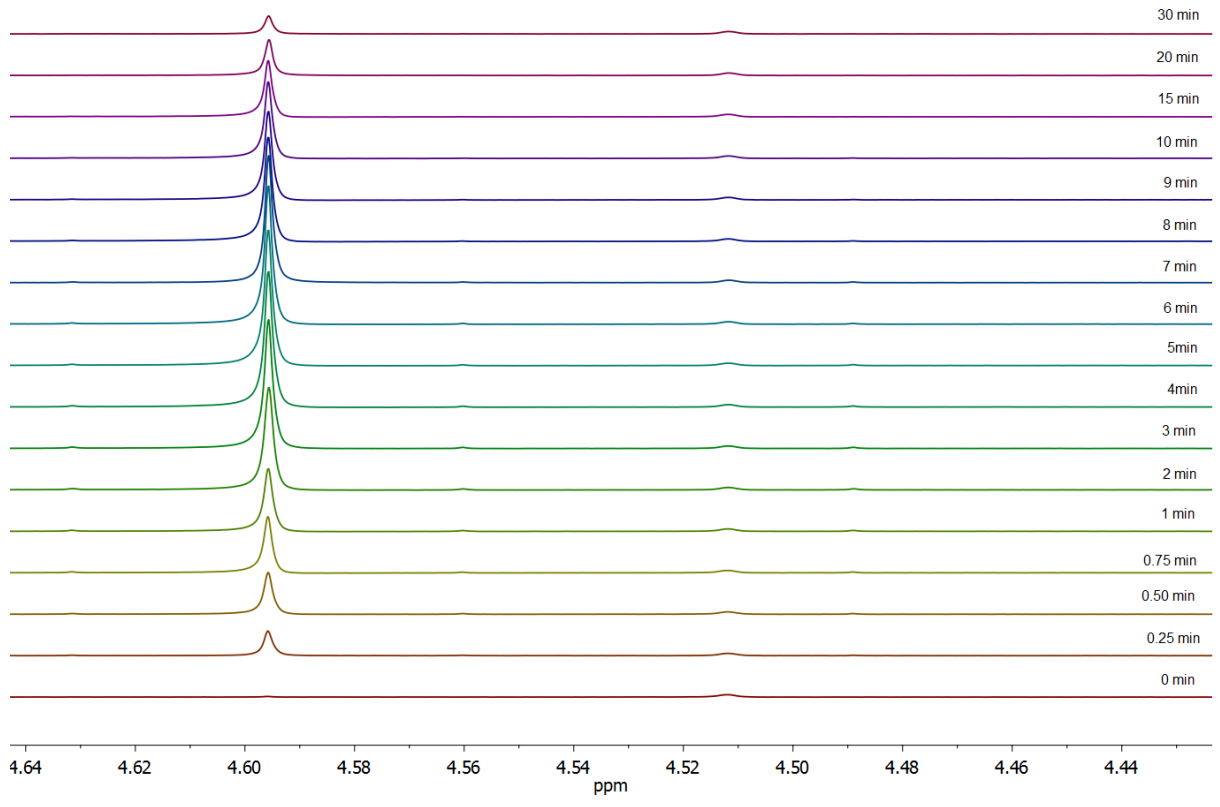

Figure S11. Representative ${ }^{1} \mathrm{H}$ NMR spectra showing the evolution of the $\mathrm{H}_{2}$ upon irradiation with $460 \mathrm{~nm}$ light of solutions [Cp* $\operatorname{Ir}(\mathrm{bpy}) \mathrm{H}]\left[\mathrm{PF}_{6}\right]$ in $\mathrm{CD}_{3} \mathrm{CN}$ in the presence of $100 \mathrm{mM} \mathrm{CH}_{3} \mathrm{CO}_{2} \mathrm{H}$ and $50 \mathrm{mM}$ mesitylene for a given amount of total irradiation time. Data presented for sample of $[\mathrm{Cp} * \mathrm{Ir}(\mathrm{bpy}) \mathrm{H}]\left[\mathrm{PF}_{6}\right]$ with an initial concentration of 11.6 mM. No HD detected.

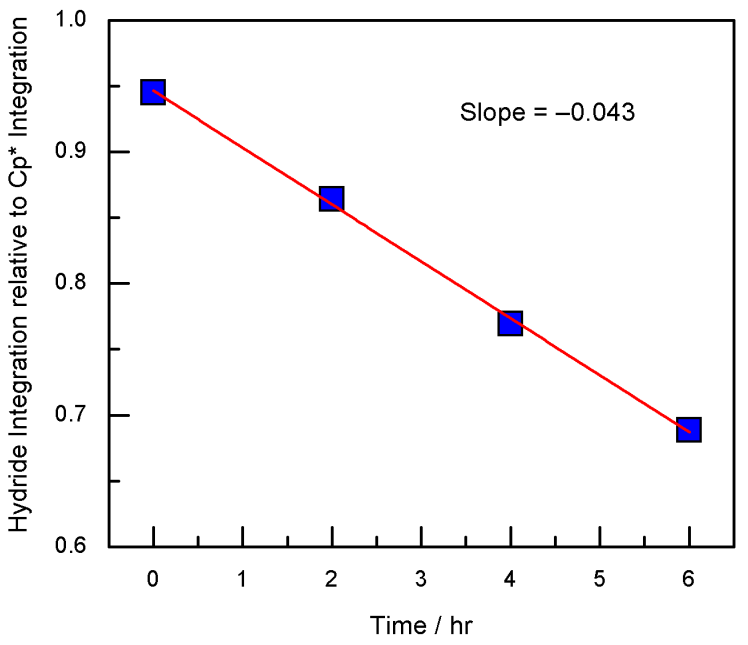

Figure S12. Integration of the $\mathrm{Ir}-\mathrm{H}$ resonance of a $21.4 \mathrm{mM}$ solution of $[\mathrm{Cp} * \operatorname{Ir}(\mathrm{bpy}) \mathrm{H}]\left[\mathrm{PF}_{6}\right]$ in $\mathrm{CD}_{3} \mathrm{CN}$ in the presence of $100 \mathrm{mM} \mathrm{CD}_{3} \mathrm{CO}_{2} \mathrm{D}$ and $50 \mathrm{mM}$ mesitylene when kept in the dark for 6 hours. The integration is relative to the $\mathrm{Cp}^{*}$ resonance of $[\mathrm{Cp} * \operatorname{Ir}(\mathrm{bpy}) \mathrm{H}]\left[\mathrm{PF}_{6}\right]$, which is set to 15 . The diminishing signal correlates to about $4.5 \% \mathrm{H} / \mathrm{D}$ exchange per hour. A typical photochemical experiment monitored by ${ }^{1} \mathrm{H}$ NMR was initiated within 15 minutes of sample preparation, resulting in an expected $1 \% \mathrm{H} / \mathrm{D}$ exchange prior to the initial measurements. 


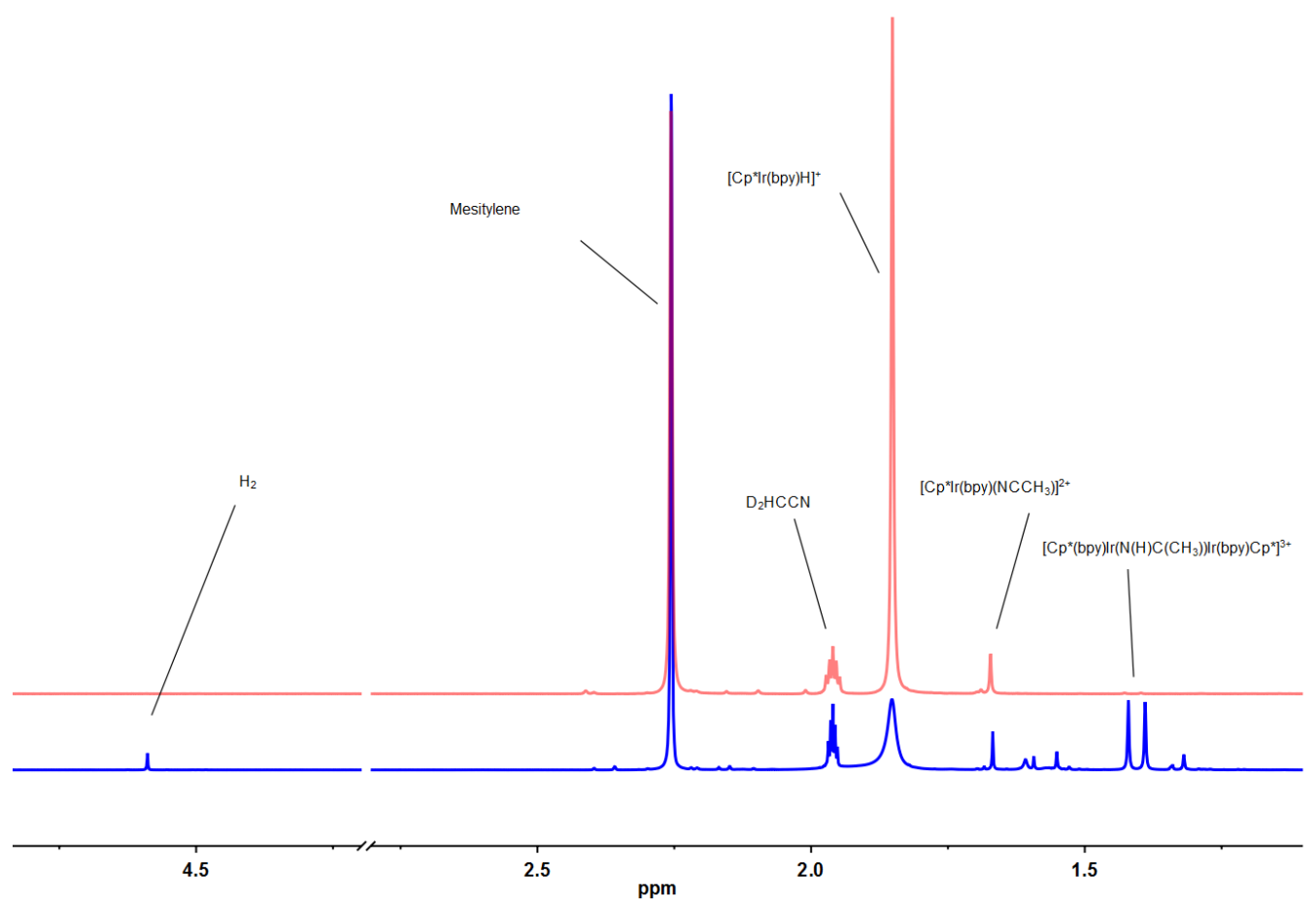

Figure S13. ${ }^{1} \mathrm{H}$ NMR spectra showing response of $[\mathrm{Cp} * \operatorname{Ir}(\mathrm{bpy}) \mathrm{H}]\left[\mathrm{PF}_{6}\right]$ in $\mathrm{CD}_{3} \mathrm{CN}$ upon irradiation with $460 \mathrm{~nm}$ light of in the absence of acid with a $50 \mathrm{mM}$ mesitylene standard. The red spectrum is prior to photolysis and the blue is after 30 minutes of irradiation. $\mathrm{H} 2$ is detected along with the primary Ir-containing product observed being the previously the characterized $\left[\mathrm{Cp} *(\mathrm{bpy}) \operatorname{Ir}\left(\mathrm{N}(\mathrm{H}) \mathrm{C}\left(\mathrm{CH}_{3}\right)\right) \operatorname{Ir}(\mathrm{bpy}) \mathrm{Cp}^{*}\right]^{3+}$ complex. ${ }^{14}$ Small amounts of $\left[\mathrm{Cp} * \operatorname{Ir}(\mathrm{bpy})\left(\mathrm{NCCH}_{3}\right)\right]^{+}$were present in the starting material did not change throughout the photolysis. 


\section{Quantum Yield Determinations}

\section{Photon Flux Calibration}

Lamp intensity was calibrated by chemical actinometry using potassium ferrioxalate and following established protocols. ${ }^{16}$ The procedure monitors the following reactions:

$$
2 \mathrm{Fe}^{3+}+\mathrm{C}_{2} \mathrm{O}_{4}^{2-} \stackrel{\mathrm{h} v}{\longrightarrow} 2 \mathrm{Fe}^{2+}+2 \mathrm{CO}_{2}
$$

The presence of $\mathrm{Fe}^{2+}$ was detected through the addition of excess phenanthroline and formation of $\left[\mathrm{Fe}(\text { phen })_{3}\right]^{2+}$, which has a diagnostic absorption at $510 \mathrm{~nm}$ with an extinction coefficient of $1.11 \times 10^{4} \mathrm{M}^{-1} \mathrm{~cm}^{-1}$. The quantum efficiency for the formation of $\mathrm{Fe}^{2+}$ upon irradiation with $443 \mathrm{~nm}$ light is reported to be 1.0 . $^{16}$ The absorption at $510 \mathrm{~nm}$ can be correlated to moles of $\mathrm{Fe}^{2+}$ which equals the moles of photons striking the sample for a given irradiation time.

The following equation was used to calculate the photon flux for the sample geometry used:

$$
I=\frac{A V_{2} V_{3}}{\varepsilon d \phi_{443} t V_{1}}
$$

where

$\mathrm{I}=$ photon flux with units of einsteins $\min ^{-1}$ sample $^{-1}$

$\mathrm{A}=$ absorbance at $510 \mathrm{~nm}$ or irradiated actinometer solution corrected for absorption of blank

$\mathrm{d}=$ path length (in $\mathrm{cm}$ ) of cell used in measurement of $\mathrm{A}$

$\varepsilon=$ extinction coefficient of $\left[\mathrm{Fe}(\text { phen })_{3}\right]^{2+}$ at $510 \mathrm{~nm}$, taken to be $1.11 \times 10^{4} \mathrm{M}^{-1} \mathrm{~cm}^{-1}$

$\phi_{443}=$ quantum yield of $\mathrm{Fe}^{2+}$ photo-generation with $443 \mathrm{~nm}$ irradiation, reported to be 1.0.

$V_{1}=$ volume (in $\mathrm{mL}$ ) or irradiated actinometer solution aliquot taken, $1 \mathrm{~mL}$ for this procedure

$V_{2}=$ volume (in $\mathrm{L}$ ) of actinometer solution irradiated, $0.002 \mathrm{~L}$ for this procedure

$V_{3}=$ volume (in $\mathrm{mL}$ ) of volumetric flask used for dilution of aliquot, $10 \mathrm{~mL}$ for this procedure $\mathrm{t}=$ irradiated time in minutes, $0.25 \mathrm{~min}$ for this procedure

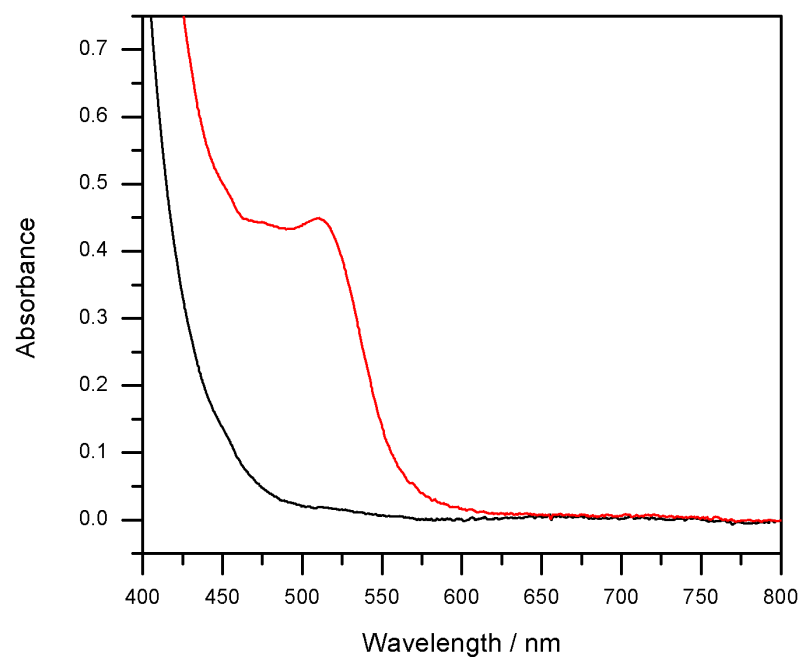

Figure S14. Representative data for detection of $\left[\mathrm{Fe}(\mathrm{phen})_{3}\right]^{2+}$ by $\mathrm{UV}$-vis during actinometer procedure. Black trace is blank and red trace is irradiated sample. 
The lamp intensity was determined using four different DC4100 driver applied current settings: $250,500,750$, and $1000 \mathrm{~mA}$. For each current setting, the average of four actinometer samples was taken as the photon flux. A linear relationship was found for applied current and photon flux as depicted below.

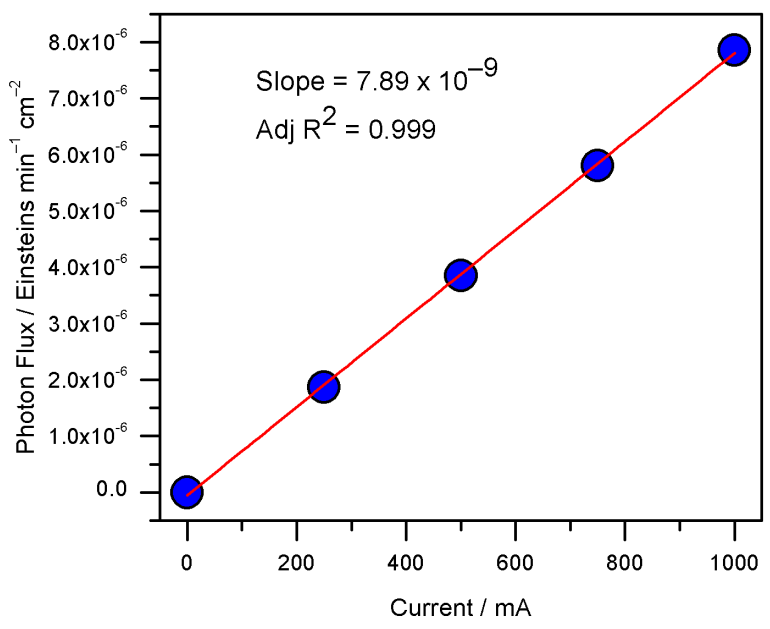

Figure S15. Calibration of photon flux of 443nm LED light source at various Driver settings for applied current.

The following relationship can be used to estimate the photo flux for a given sample and a given current setting in units of "moles of photons $\mathrm{min}^{-1} \mathrm{~cm}^{-2}$ ":

Photon Flux $=7.89 \times 10^{-9} \times$ Current $(\mathrm{mA}) \times$ irradiated surface area $\left(\mathrm{cm}^{2}\right)$

Unless otherwise stated, an applied current of $250 \mathrm{~mA}$ and an irradiated surface area of 2 $\mathrm{cm}^{2}$ was used within this study. These conditions resulted in a photon flux of $3.94 \times 10^{-6}$ moles of photons per minute per sample. The flux was not observed to vary significantly during the course of data collection for this manuscript.

\section{Representative Example of Quantum Yield Determination for 1}

All samples were prepared within an $\mathrm{N}_{2}$-filled glovebox using a $1 \mathrm{~cm}$ path length quartz cuvette with a screw cap. Solutions of $\left[\mathrm{Cp}^{*} \operatorname{Ir}(\mathrm{bpy}) \mathrm{H}\right]\left[\mathrm{PF}_{6}\right](\mathbf{1})$ were prepared using acetonitrile. Unless otherwise noted, $\mathrm{CH}_{3} \mathrm{CO}_{2} \mathrm{H}$ was used as a proton source under pseudo-first order conditions. Upon removal from the glovebox, the caps were reinforced by wrapping with parafilm prior to irradiation with a $443 \mathrm{~nm}$ light source. The photochemical setup was identical to that used for the lamp intensity calibration.

The photochemical reaction of 1 was monitored by UV-vis. The decay of the diagnostic MLCT feature at $428 \mathrm{~nm}$ for 1 was tracked during the course of irradiation with $443 \mathrm{~nm}$ light by $\mathrm{UV}$-vis. For a representative example of quantum yield determination, we can consider a 0.12 mM sample of 1 in $\mathrm{CH}_{3} \mathrm{CN}$ in the presence $50 \mathrm{mM} \mathrm{CH}_{3} \mathrm{CO}_{2} \mathrm{H}$. 


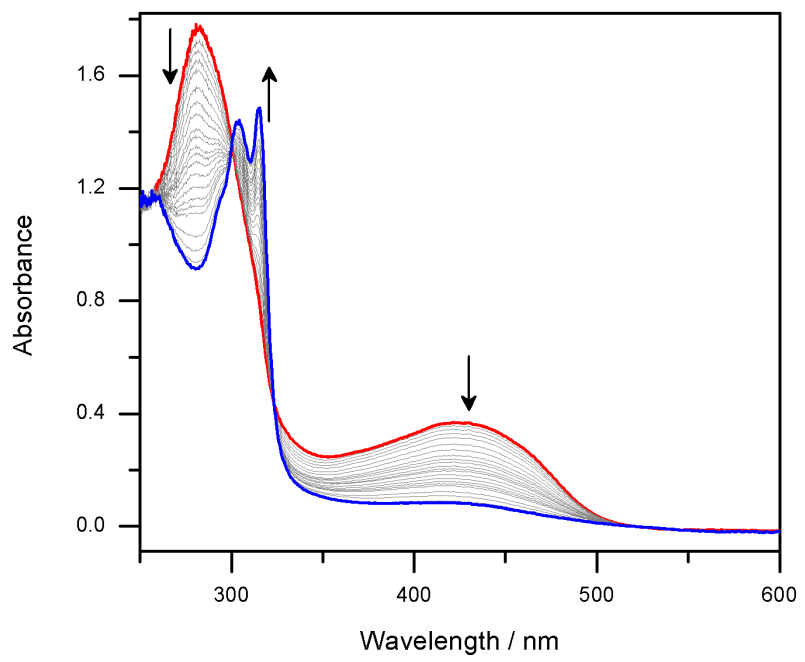

Figure S16. UV-vis spectral evolution of $0.12 \mathrm{mM} 1$ in $\mathrm{CH}_{3} \mathrm{CN}$ in the presence of $50 \mathrm{mM} \mathrm{CH}_{3} \mathrm{CO}_{2} \mathrm{H}$. Samples irradiated for 30 minutes with $443 \mathrm{~nm}$ LED light source. Initial spectrum in red. Final spectrum in blue. Decay of signal at $428 \mathrm{~nm}$ used to calculate concentration of $\mathbf{1}$.

When the initial absorbance at $428 \mathrm{~nm}$ was near or below 1, the extinction coefficient of 1 at $428 \mathrm{~nm}\left(2.9 \times 10^{4} \mathrm{M}^{-1} \mathrm{~cm}^{-2}\right)$ was used to calculate the [1] at each time point. When the absorption at $428 \mathrm{~nm}$ was either too high or too low, a wavelength with an initial absorbance near 1 was monitored using the appropriate extinction coefficient.

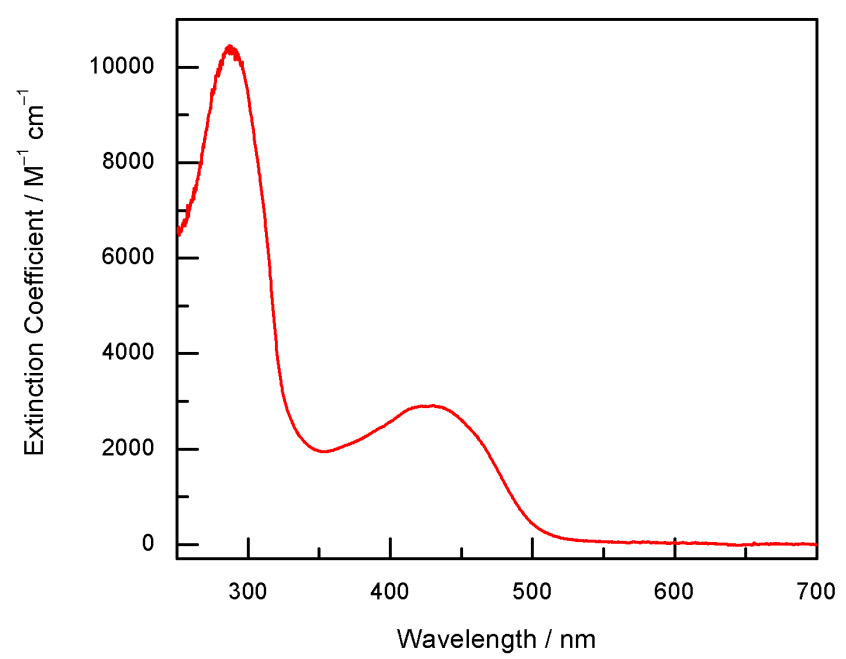

Figure S17. UV-vis absorption spectrum of 1 in $\mathrm{CH}_{3} \mathrm{CN}$.

The resulting kinetic trace of [1] versus time can be evaluated using initial rates methods to determine a rate of reaction. For the example in Figure S16. The slope of initial time points affords a rate of decay of $1.26 \times 10^{-5} \mathrm{M}^{-1} \mathrm{~s}^{-1}$. 


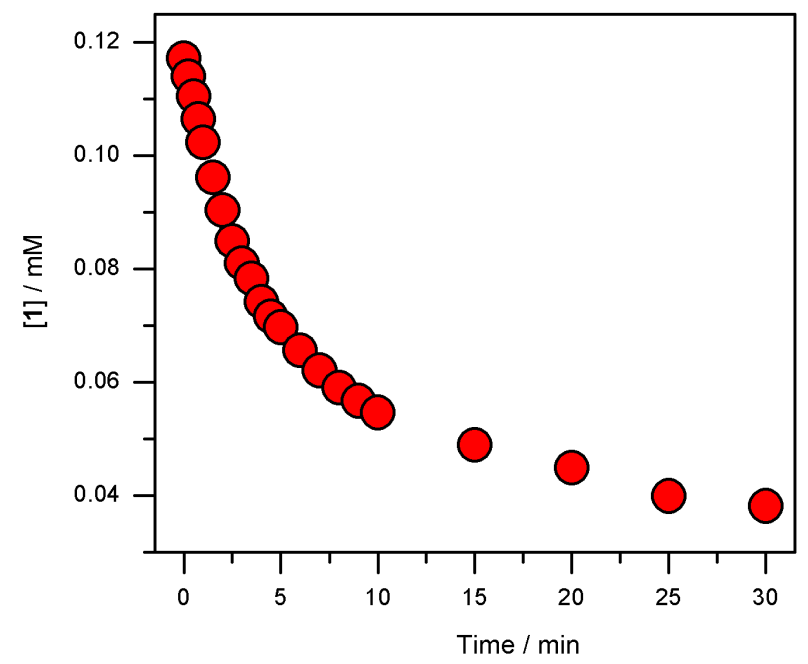

Figure S18. Kinetic decay of [1] upon irradiation of a solution a $0.12 \mathrm{mM} 1$ in $\mathrm{CH}_{3} \mathrm{CN}$ with $50 \mathrm{mM} \mathrm{CH}_{3} \mathrm{CO}_{2} \mathrm{H}$ upon irradiation with $443 \mathrm{~nm}$ LED light source.

Next, the initial rate needs to be converted to the units of "moles $\min ^{-1}$ " by multiplying the sample volume in liters $(0.002 \mathrm{~L})$. This results in a rate of decay of the starting material of $2.52 \times 10^{-8}$ moles $\min ^{-1}$.

The decay of the starting material was taken to be equal to the growth of product. Quantum yields were calculated using the following relationship

$$
\Phi=\frac{\text { Initial Rate of decay of } \mathbf{1} \text { in moles } / \mathrm{min}}{\text { Absorbed Photon flux in moles } / \mathrm{min}}
$$

Given the calibration of the photochemical setup and parameters used, the photon flux irradiating the sample was $3.94 \times 10^{-6}$ moles of photons per minute. The following correction needs to be applied to calculated photons absorbed by the sample:

$$
\text { Absorbed Photons }=\text { Total Photon Flux } \times\left(1-10^{-A_{443}}\right)
$$

with $\mathrm{A}_{443}$ being the initial absorption of the irradiated sample at $443 \mathrm{~nm}$. For this example, $\mathrm{A}_{443}$ is 0.343 which results in an absorbed photon flux of $2.15 \times 10^{-6}$ moles of photons $\mathrm{min}^{-1}$. Overall, this affords a quantum yield of $1.2 \times 10^{-2}$. 


\section{Quantum Yields as a function of [1]}

Table S2. Quantum yields for the photo-initiated decay of 1 upon irradiation with $443 \mathrm{~nm}$ light in $\mathrm{CH}_{3} \mathrm{CN}$ in the presence of excess $\mathrm{CH}_{3} \mathrm{CO}_{2} \mathrm{H}$ at various concentrations of $\mathbf{1}$.

\begin{tabular}{|c|c|}
\hline$[1] / \mathrm{mM}$ & Quantum Yield \\
\hline 0.018 & 0.0011 \\
\hline 0.018 & 0.0012 \\
\hline 0.020 & 0.002 \\
\hline 0.020 & 0.00086 \\
\hline 0.024 & 0.0011 \\
\hline 0.024 & 0.0012 \\
\hline 0.047 & 0.0043 \\
\hline 0.048 & 0.0047 \\
\hline 0.049 & 0.0050 \\
\hline 0.051 & 0.0039 \\
\hline 0.061 & 0.0036 \\
\hline 0.061 & 0.0036 \\
\hline 0.106 & 0.0093 \\
\hline 0.108 & 0.0088 \\
\hline 0.117 & 0.0095 \\
\hline 0.117 & 0.011 \\
\hline 0.123 & 0.011 \\
\hline 0.587 & 0.080 \\
\hline 0.590 & 0.065 \\
\hline 0.590 & 0.063 \\
\hline 0.590 & 0.071 \\
\hline 0.590 & 0.072 \\
\hline 0.591 & 0.074 \\
\hline 0.593 & 0.067 \\
\hline 0.604 & 0.082 \\
\hline 0.613 & 0.071 \\
\hline 0.616 & 0.081 \\
\hline
\end{tabular}

\begin{tabular}{|c|c|}
\hline$[1] / \mathrm{mM}$ & Quantum Yield \\
\hline 0.616 & 0.072 \\
\hline 0.626 & 0.058 \\
\hline 0.629 & 0.059 \\
\hline 0.636 & 0.061 \\
\hline 0.638 & 0.064 \\
\hline 0.641 & 0.055 \\
\hline 0.690 & 0.068 \\
\hline 0.705 & 0.061 \\
\hline 0.708 & 0.063 \\
\hline 0.712 & 0.068 \\
\hline 0.713 & 0.065 \\
\hline 0.794 & 0.090 \\
\hline 0.800 & 0.091 \\
\hline 0.801 & 0.090 \\
\hline 0.850 & 0.091 \\
\hline 0.994 & 0.080 \\
\hline 2.00 & 0.16 \\
\hline 2.00 & 0.17 \\
\hline 2.06 & 0.19 \\
\hline 2.86 & 0.21 \\
\hline 3.12 & 0.27 \\
\hline 5.64 & 0.48 \\
\hline 6.25 & 0.52 \\
\hline 10.9 & 0.79 \\
\hline 12.5 & 0.86 \\
\hline 18.8 & 0.93 \\
\hline 25 & 0.98 \\
\hline
\end{tabular}




\section{Quantum Yields as a function of 1 using $\left[\mathrm{Et}_{3} \mathrm{NH}\right]\left[\mathrm{BF}_{4}\right]$ as an acid source}

Table S3. Quantum yields for the photo-initiated decay of 1 upon irradiation with $443 \mathrm{~nm}$ light in $\mathrm{CH}_{3} \mathrm{CN}$ in the presence of $100 \mathrm{mM}\left[\mathrm{Et}_{3} \mathrm{NH}\right]\left[\mathrm{BF}_{4}\right]$ at various concentrations of $\mathbf{1}$.

\begin{tabular}{|c|c|}
\hline$[1] / \mathrm{mM}$ & Quantum Yield \\
\hline 0.018 & 0.0010 \\
\hline 0.049 & 0.0039 \\
\hline 0.125 & 0.013 \\
\hline 0.589 & 0.077 \\
\hline 2.01 & 0.18 \\
\hline
\end{tabular}

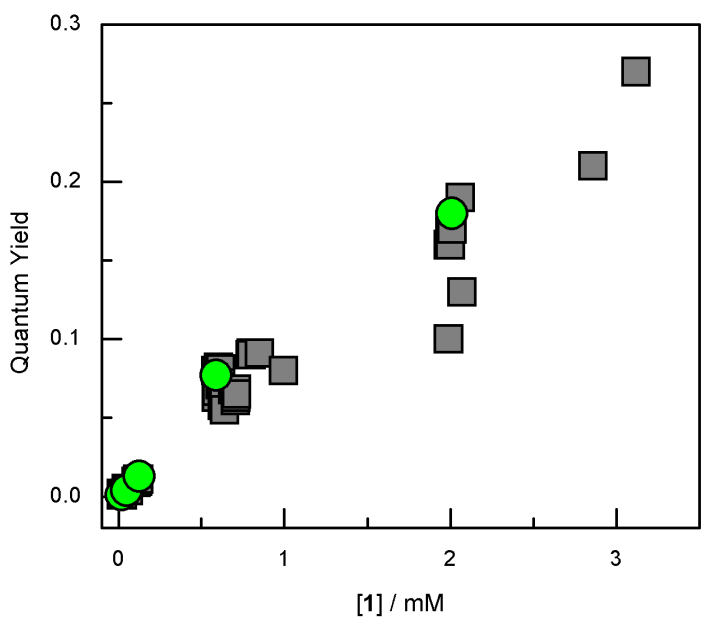

Figure S19. Comparison of quantum yields for the photo-initiated decay of 1 at various concentrations in $\mathrm{CH}_{3} \mathrm{CN}$ in the presence of excess $\mathrm{CH}_{3} \mathrm{CO}_{2} \mathrm{H}$ (grey squares) or $\left[\mathrm{Et}_{3} \mathrm{NH}\right]\left[\mathrm{BF}_{4}\right]$ (green circles).

\section{Quantum Yield Dependence on Incident Photon Flux}

Table S4. Quantum yields for the photo-initiated decay of $0.55 \mathrm{mM}$ solutions of 1 upon irradiation with $443 \mathrm{~nm}$ light in $\mathrm{CH}_{3} \mathrm{CN}$ in the presence of $50 \mathrm{mM} \mathrm{CH}_{3} \mathrm{CO}_{2} \mathrm{H}$ at various incident photon fluxes.

\begin{tabular}{|c|c|}
\hline $\begin{array}{c}\text { Incident Photon Flux / } \\
\text { mols photons min }\end{array} \mathrm{cm}^{-2}$ & Quantum Yield \\
\hline $1.97 \mathrm{E}-06$ & 0.079 \\
\hline $3.95 \mathrm{E}-06$ & 0.073 \\
\hline $7.89 \mathrm{E}-06$ & 0.071 \\
\hline $1.18 \mathrm{E}-05$ & 0.071 \\
\hline $1.58 \mathrm{E}-05$ & 0.065 \\
\hline
\end{tabular}




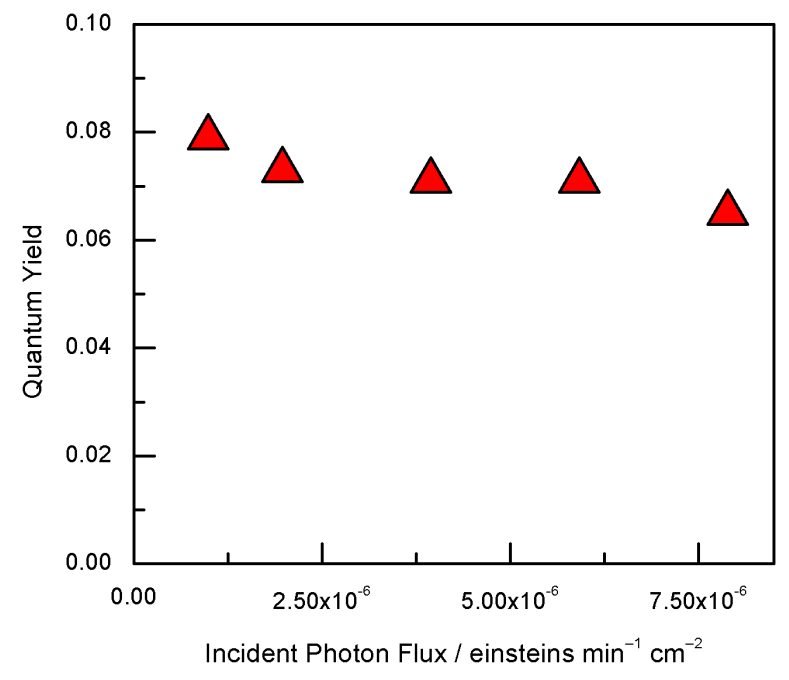

Figure S20. Quantum yields for the photo-initiated decay of $0.55 \mathrm{mM}$ solutions of 1 upon irradiation with $443 \mathrm{~nm}$ light in $\mathrm{CH}_{3} \mathrm{CN}$ in the presence of excess $\mathrm{CH}_{3} \mathrm{CO}_{2} \mathrm{H}$ at various incident photon fluxes.

\section{Quantum Yields as a Function of Isotopically Labeled Hydride}

Table S5. Quantum yields for the photo-initiated decay of 1-D upon irradiation with $443 \mathrm{~nm}$ light in $\mathrm{CH}_{3} \mathrm{CN}$ in the presence of $50 \mathrm{mM} \mathrm{CH} \mathrm{CO}_{2} \mathrm{H}$ at various concentrations of 1-D.

\begin{tabular}{|c|c|}
\hline$[\mathbf{1}-\mathbf{D}] / \mathrm{mM}$ & Quantum Yield \\
\hline 0.85 & 0.071 \\
\hline 1 & 0.089 \\
\hline 1 & 0.091 \\
\hline 1 & 0.090 \\
\hline 2.1 & 0.18 \\
\hline 4.2 & 0.39 \\
\hline 8.5 & 0.62 \\
\hline 12.8 & 0.87 \\
\hline 17 & 0.88 \\
\hline
\end{tabular}




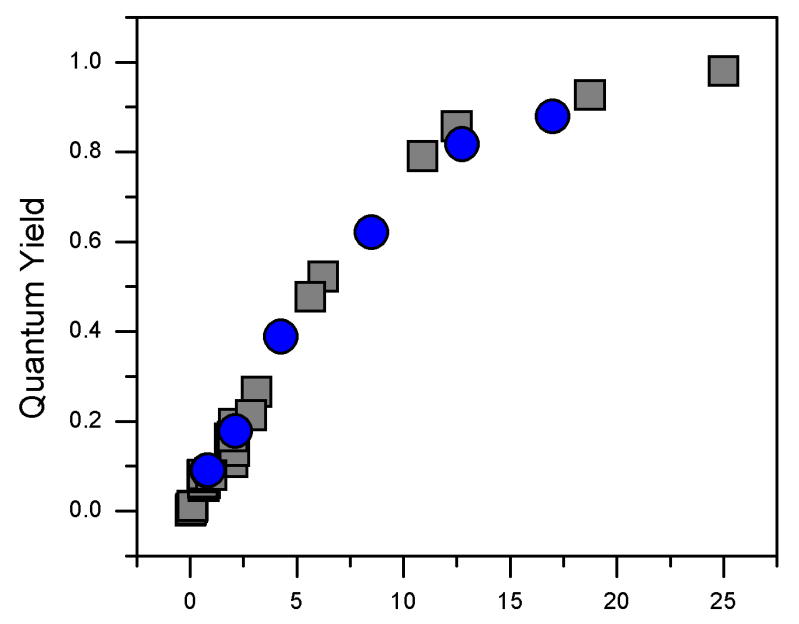

[1] or [1-D] / mM

Figure S21. Concentration dependent quantum yields for the photo-initiated decay of $\mathbf{1}$ and 1-D upon irradiation with $443 \mathrm{~nm}$ light in $\mathrm{CH}_{3} \mathrm{CN}$ in the presence of $50 \mathrm{mM} \mathrm{CD}_{3} \mathrm{CO}_{2} \mathrm{D}$ at various incident photon fluxes. No significant KIE is observed.

\section{Quantum Yield Dependence on Electrolyte Concentration}

Table S6. Quantum yields for the photo-initiated decay of 1 upon irradiation with $443 \mathrm{~nm}$ light in $\mathrm{CH}_{3} \mathrm{CN}$ in the presence of $50 \mathrm{mM} \mathrm{CH}_{3} \mathrm{CO}_{2} \mathrm{H}$ without electrolyte and with $100 \mathrm{mM}$ of $\left[\mathrm{Bu}_{4} \mathrm{~N}\right]\left[\mathrm{PF}_{6}\right]$ run in triplicate

\begin{tabular}{|c|c|c|}
\hline $\mathbf{1} / \mathbf{m M}$ & {$\left[\mathbf{B u}_{\mathbf{4}} \mathbf{N}\right]\left[\mathbf{P F}_{\mathbf{6}}\right] / \mathbf{m M}$} & Quantum Yield \\
\hline 0.48 & 0 & 0.044 \\
\hline 0.48 & 0 & 0.045 \\
\hline 0.48 & 0 & 0.044 \\
\hline 0.48 & 100 & 0.089 \\
\hline 0.48 & 100 & 0.090 \\
\hline 0.48 & 100 & 0.091 \\
\hline
\end{tabular}

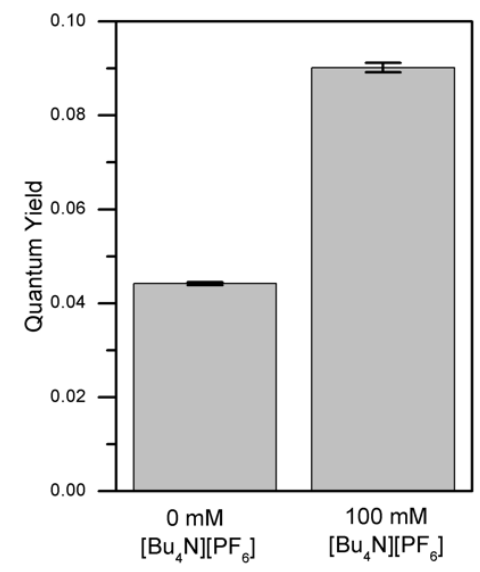

Figure S22. Comparing the average quantum yield measurement for the photo-initiated decay of $0.46 \mathrm{mM}$ solution of 1 in $\mathrm{CH}_{3} \mathrm{CN}$ upon irradiation with $443 \mathrm{~nm}$ light in the presence of $50 \mathrm{mM} \mathrm{CH}_{3} \mathrm{CO}_{2} \mathrm{H}$ without electrolyte and with $100 \mathrm{mM}$ of $\left[\mathrm{Bu}_{4} \mathrm{~N}\right]\left[\mathrm{PF}_{6}\right]$. Error bars represent standard deviation. 


\section{VI. $\Delta \mathbf{G}_{\mathrm{sT}}$ Considerations}

Experimental Considerations Photoluminescence Emission Spectroscopy

All samples for emission data were prepared in a $\mathrm{N}_{2}$-filled glovebox. For room temperature data, solutions of 1 were made in $\mathrm{CH}_{3} \mathrm{CN}$ and transfers to a $1 \mathrm{~cm}$ path length quartz cuvette and sealed with a screw cap. Upon removal from the glovebox, the seal of the caps was immediately reinforced with parafilm.

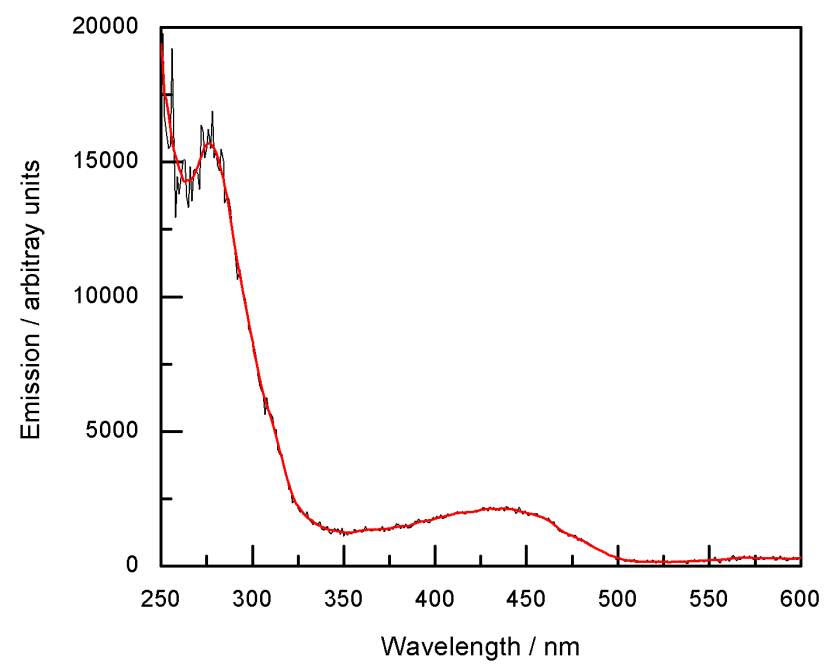

Figure S23 Room temperature excitation spectra under an atmosphere of $\mathrm{N}_{2}$ of $0.1 \mathrm{mM} 1$ in $\mathrm{CH}_{3} \mathrm{CN}$ (black) with smoothed trace overlaid (red). Emission detected at $708 \mathrm{~nm}$.

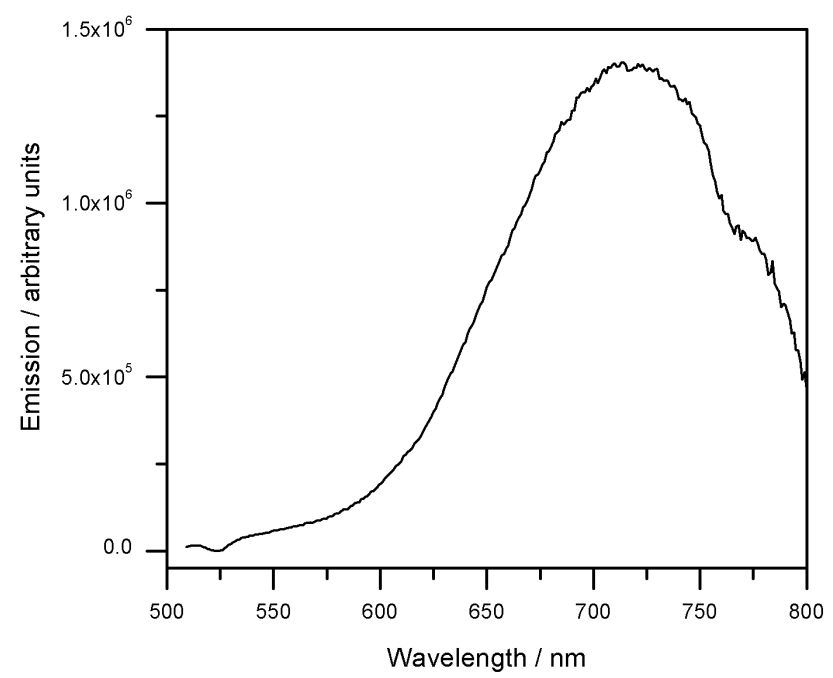

Figure S24. Room temperature emission spectra under an atmosphere of $\mathrm{N}_{2}$ of $0.1 \mathrm{mM} 1$ in $\mathrm{CH}_{3} \mathrm{CN}$ (black). Excitation at $428 \mathrm{~nm}$. 


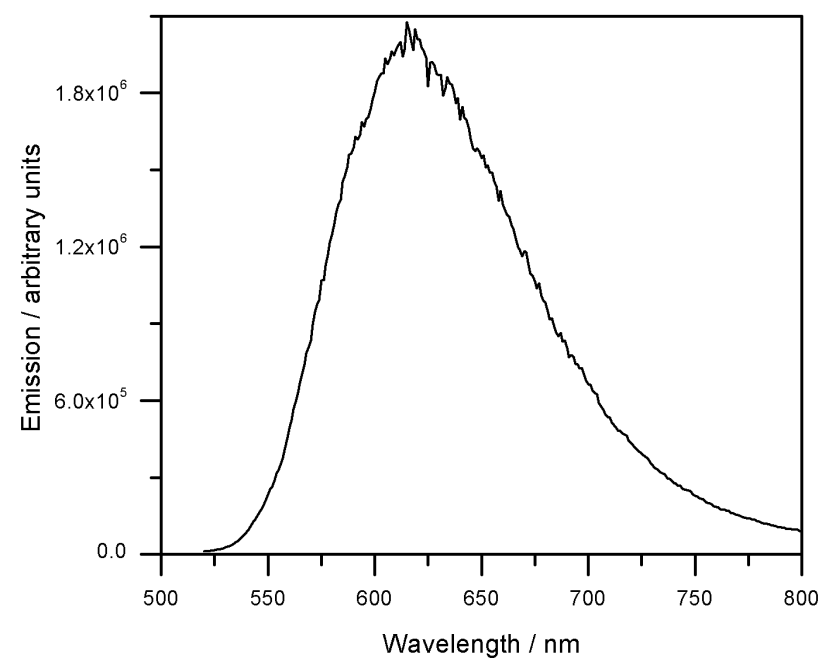

Figure S25. Emission spectra under an atmosphere of $\mathrm{N}_{2}$ of $2.0 \mathrm{mM} 1$ at $77 \mathrm{~K}$ in frozen glass of $4: 5$ propionitrile:butyronitrile (black). Excitation at $428 \mathrm{~nm}$.

\section{Determining Range of $\Delta \mathrm{G}_{\mathrm{ST}}$}

Determining $\Delta \mathrm{G}_{\mathrm{ST}}$ required a value for the lowest vibrational level of the excited state, $\mathrm{E}_{00}$. $\mathrm{E}_{00}$ is typically estimated by three different methods. The first method takes the intersection of the normalized emission spectrum and excitation spectrum as the energy of $\mathrm{E}_{00}$. For $\mathbf{1}$, no such intersection is observed and thus this method cannot be used to obtain a value of $E_{00}$.

A second method takes the y-intercept of the line tangent to the high energy slope of the emission feature as a value for $\mathrm{E}_{00}$. We have previously used this method to report an $\mathrm{E}_{00}$ of $\mathbf{1}$ at room temperature in $\mathrm{CH}_{3} \mathrm{CN}$ of $16,900 \mathrm{~cm}^{-1}(48.3 \mathrm{kcal} / \mathrm{mol}) .{ }^{14}$ We can apply this method to the emission at $77 \mathrm{~K}$ within Figure S23 and slightly a different value of $18,300 \mathrm{~cm}^{-1}(52.3 \mathrm{kcal} / \mathrm{mol})$

A third method utilizes a single mode, Franck-Condon analysis of emission spectra for $\mathbf{1}$ (see experimental details for method) with the quantum spacing, $\hbar \omega_{\mathrm{M}}$, varied from $1100-1500 \mathrm{~cm}^{-1}$ yielded a range of values for $\mathrm{S}_{\mathrm{M}}$ of $0.95-0.52$, for $\Delta \tilde{v}_{0,1 / 2}$ of $1869-2147 \mathrm{~cm}^{-1}$, and for $E_{0}$ of 16570 $16280 \mathrm{~cm}^{-1}$. A representative spectral fits using $\hbar \omega_{\mathrm{M}}=1100 \mathrm{~cm}^{-1}$ is shown Fig S24. Plotting the value of $\hbar \omega_{M}$ versus the resulting value of $E_{00}$ results in a range of $E_{00}$ between $16558 \mathrm{~cm}^{-1}(47.3$ $\mathrm{kcal} / \mathrm{mol})$ and $16276.8 \mathrm{~cm}^{-1}(46.5 \mathrm{kcal} / \mathrm{mol})$. This represents a linear relationship between the value of $\hbar \omega$ used in the fitting and the resulting value of $\mathrm{E}_{00}$ (Figure $\mathrm{S} 25$ ). Typical $\hbar \omega_{\mathrm{M}}$ for related $\left[\mathrm{Ru}(\text { bpy })_{3}\right]^{2+}$ organometallic complexes are around $1350 \mathrm{~cm}^{-1}$. As such, the corresponding $\mathrm{E}_{00}$ value derived using $\hbar \omega=1350 \mathrm{~cm}^{-1}$ is taken as an approximation of the $\Delta \mathrm{G}_{\mathrm{ST}}\left(16370 \mathrm{~cm}^{-1}\right)$. 

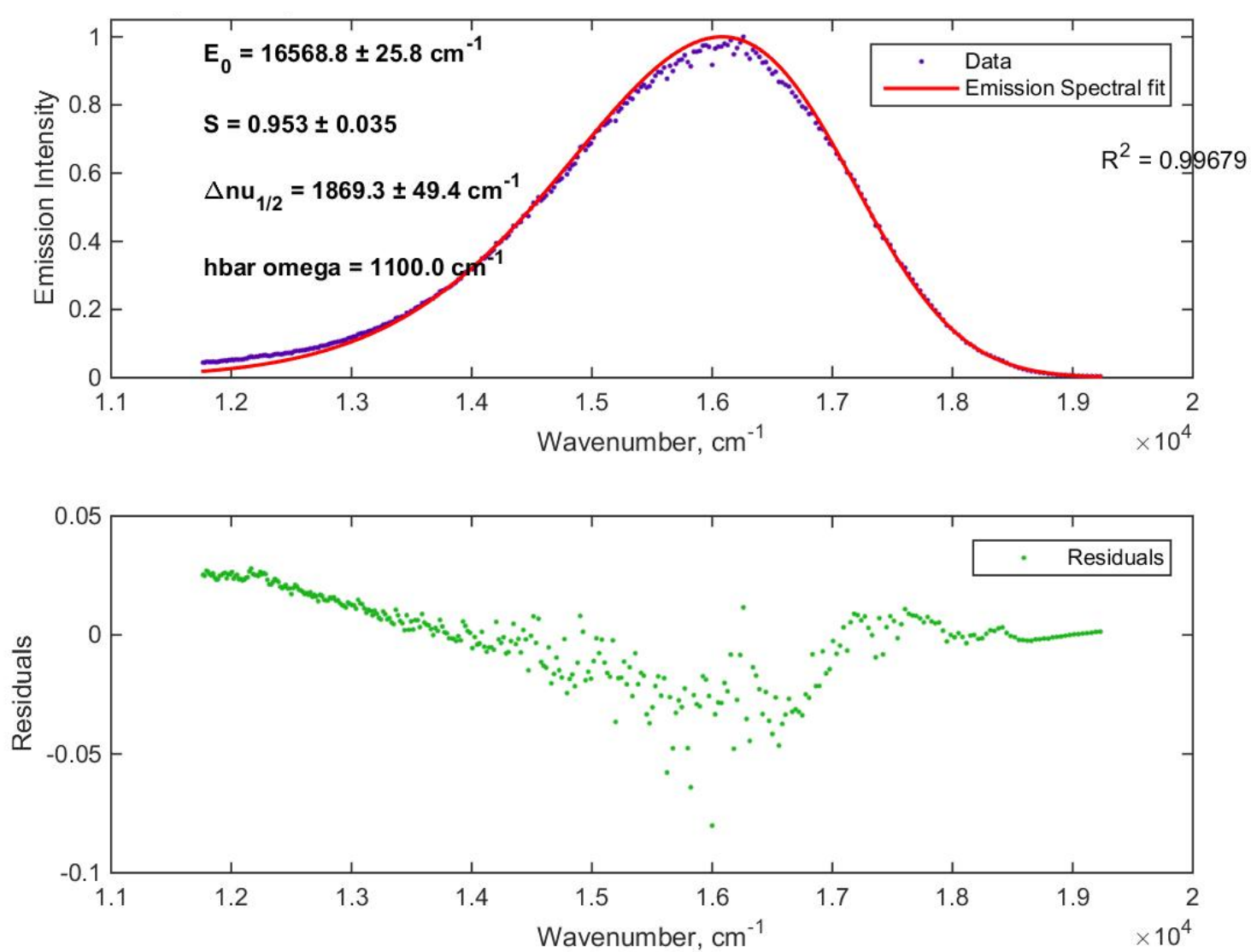

Figure S26. Fitting of $77 \mathrm{~K}$ emission spectrum of $2.0 \mathrm{mM}$ of 1 under an atmosphere of $\mathrm{N}_{2}$ of $2.0 \mathrm{mM} 1$ frozen glass of $4: 5$ propionitrile:butyronitrile with excitation at $428 \mathrm{~nm}$.

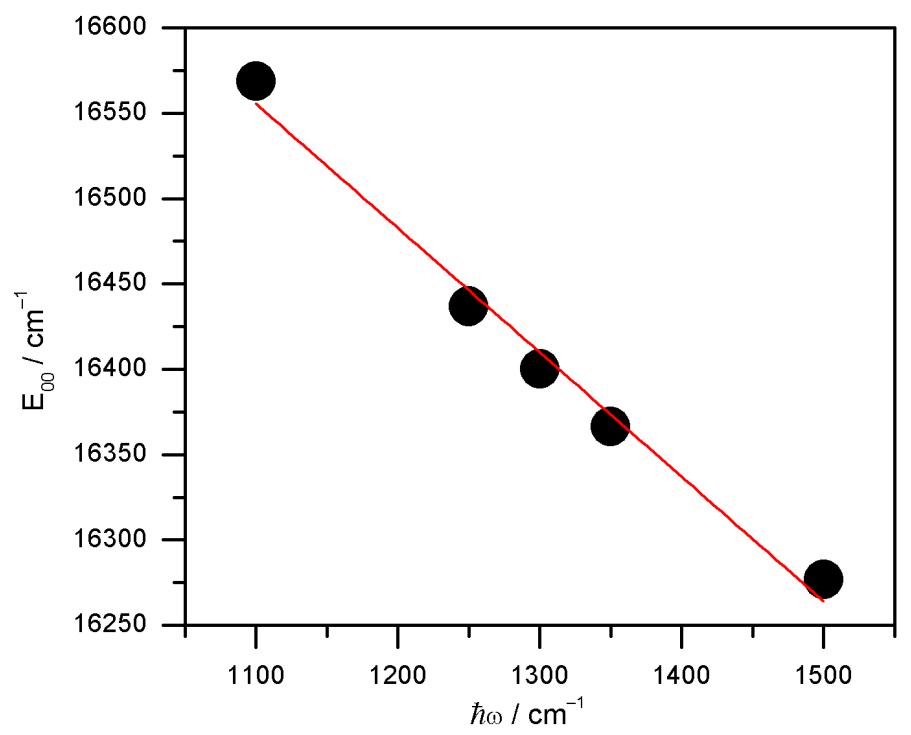

Figure S27. Value of $\mathrm{E}_{00}$ of 1 obtained from fitting of $77 \mathrm{~K}$ emission data with varying values of $\hbar \omega$ used for the fit.

Using these various methods for $\mathrm{E}_{00}$ determination, we can estimate a range of values for $\Delta \mathrm{G}_{\mathrm{ST}}$ between $52-47 \mathrm{kcal} / \mathrm{mol}$. 


\section{Steady State Photoluminescence Quenching}

The range of concentrations of 1 needed to observe changes in emission included conditions in which inner filter effect corrections needed to be applied. The correction method followed was published by Albinson and coworkers ${ }^{17}$ uses the following empirically derived relationship:

where

$$
I_{\text {corr }}{ }^{\prime}=I_{o b s} \times 10^{\varepsilon c l_{p}}
$$

$I_{\text {corr }}{ }^{\prime}=$ corrected emission without background correction

$I_{\text {obs }}=$ measured emission

$\varepsilon=$ extinction coefficient of chromophore at excitation wavelength in $\mathrm{M}^{-1} \mathrm{~cm}^{-1}$

$\mathrm{c}=$ concentration of chromophore in $\mathrm{M}$

$l_{p}=$ path length of sample being detected in fluorimeter in $\mathrm{cm}$

The value of $l_{p}$ is instrument dependent and has to be calibrated with a standard following the method described by Albinson and coworkers. Using $\left[\mathrm{Ru}(\mathrm{bpy})_{3}\right]^{2+}$ as a standard, a value of $l_{p}$ of $0.56 \mathrm{~cm}$ was determined.

Table S7. Steady State Emission data for variable concentrations of $\mathbf{1}$ in $\mathrm{CH}_{3} \mathrm{CN}$ at room temperature.

\begin{tabular}{|c|c|c|c|c|c|c|c|}
\hline$[1] / \mathbf{m M}$ & $\mathbf{I}_{\mathbf{o b s}}$ & $A_{428}{ }^{a}$ & $\mathbf{I}_{\text {corr }}{ }^{\prime}$ & $I_{\text {background }} b$ & $\mathbf{I}_{\text {corr }}{ }^{d}$ & $I_{\text {norm }}{ }^{c}$ & $\mathbf{I}_{0} / \mathbf{I}^{e}$ \\
\hline 0.52 & 3488 & 1.56 & 26226 & 257 & 25969 & 16625 & 1.127 \\
\hline 0.34 & 4873 & 1.02 & 18122 & 257 & 17866 & 17566 & 1.067 \\
\hline 0.17 & 4948 & 0.52 & 9685 & 257 & 9429 & 18129 & 1.034 \\
\hline 0.12 & 4228 & 0.35 & 6686 & 257 & 6429 & 18122 & 1.034 \\
\hline 0.05 & 2487 & 0.15 & 3014 & 257 & 2758 & 18526 & 1.012 \\
\hline
\end{tabular}

${ }^{a}$ Absorbance of sample at excitation wavelength of $428 \mathrm{~nm}$. ${ }^{b}$ Background emission measured in absence of 1 . ${ }^{\mathrm{c}}$ Normalized emission calculated by dividing $\mathrm{I}_{\text {corr }}$ by $\mathrm{A}_{428}{ }^{{ }^{d}}$ Background corrected and inner filter effect corrected emission. ${ }^{e} \mathrm{I}_{0}$ is the extrapolation of $\mathrm{I}_{\text {corr }}$ to infinite dilution of $\mathbf{1}$, which was determined to be 18741 . I is the normalized emission value.

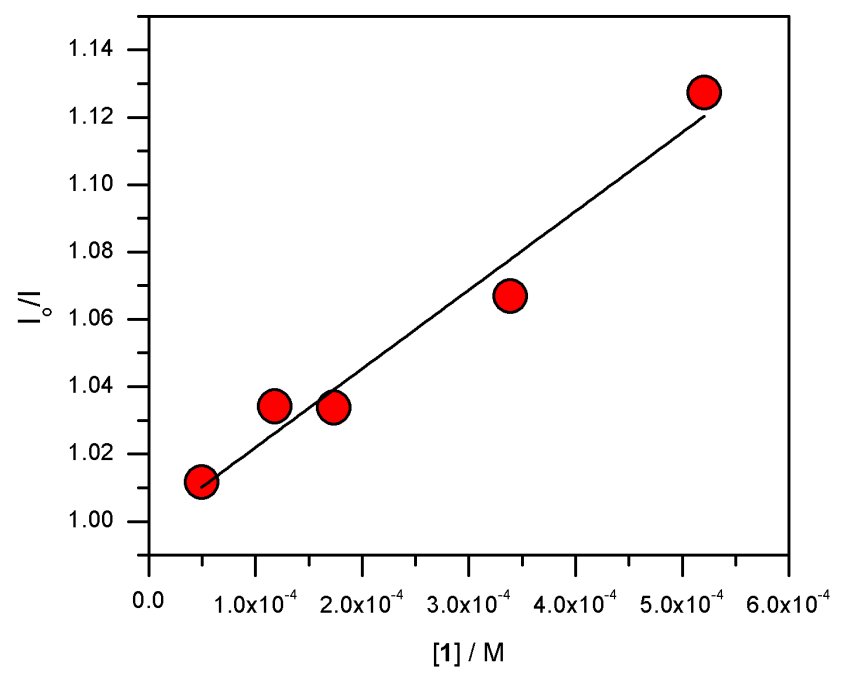

Figure S28. Self-quenching Stern-Volmer analysis for $\mathbf{1}$ in $\mathrm{CH}_{3} \mathrm{CN}$ at room temperature. $\mathrm{I}_{0}$ is the emission extrapolated to infinite dilution. I is the corrected and normalized emission at a given concentration of $\mathbf{1}$. A linear fit of the data affords a $K \mathrm{sv}$ of $233 \mathrm{M}^{-1}$. 
Table S8. Steady State emission data for $0.11 \mathrm{mM} 1$ in $\mathrm{CH}_{3} \mathrm{CN}$ with vary $\mathrm{CH}_{3} \mathrm{CO}_{2} \mathrm{H}$ concentrations at room temperature. ${ }^{a}$

\begin{tabular}{|c|c|c|c|c|c|}
\hline$\left[\mathbf{C H}_{\mathbf{3}} \mathbf{C O}_{\mathbf{2}} \mathbf{H}\right] / \mathbf{m M}$ & $\mathbf{I}_{\text {obs }}$ & $\mathbf{A 4 2 8}^{\boldsymbol{b}}$ & $\mathbf{I}_{\text {background }}{ }^{\boldsymbol{c}}$ & $\mathbf{I}_{\text {corr }}{ }^{\boldsymbol{d}}$ & $\mathbf{I}_{\mathbf{0}} / \mathbf{I}^{\boldsymbol{e}}$ \\
\hline 0.00 & 7380 & 0.39 & 353 & 7028 & 1.00 \\
\hline 0.11 & 7419 & 0.39 & 353 & 7067 & 0.99 \\
\hline 0.55 & 7348 & 0.39 & 353 & 6995 & 1.00 \\
\hline 1.11 & 7451 & 0.39 & 353 & 7099 & 0.99 \\
\hline 2.22 & 7470 & 0.39 & 353 & 7117 & 0.99 \\
\hline
\end{tabular}

${ }^{a}$ No corrections for inner filter effect or concentration normalizations were applied as those were constant since [1] was constant. ${ }^{b}$ Absorbance of sample at excitation wavelength of $428 \mathrm{~nm} .{ }^{c}$ Background emission measured in absence of $1 .{ }^{d}$ Background corrected emission. ${ }^{e} \mathrm{I}_{0}$ is emission with no acid in solution. I is the corrected emission for the given sample. These definitions define the first entry as $\mathrm{I}_{0} / \mathrm{I}=1$.

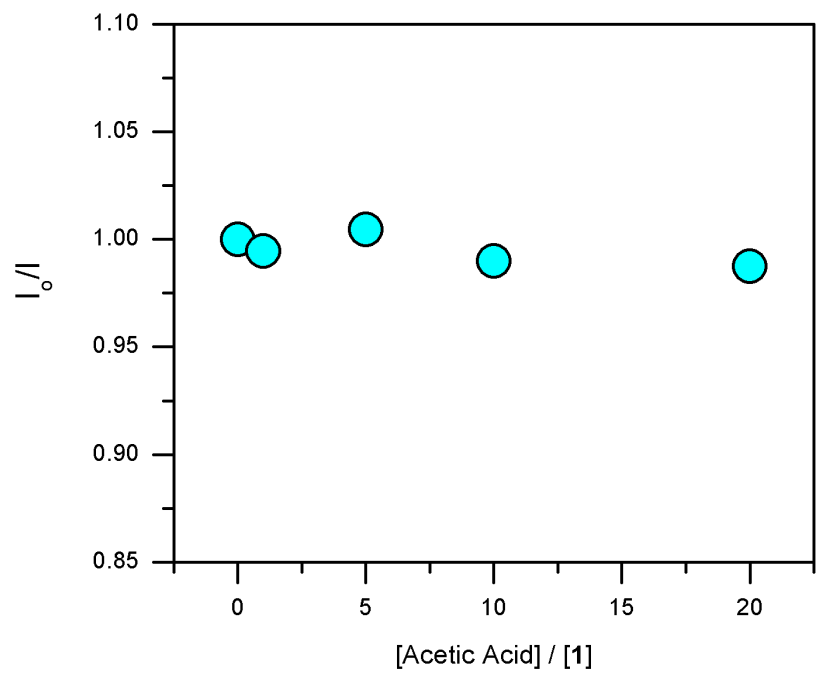

Figure S29. Acid quenching Stern-Volmer analysis for $0.11 \mathrm{mM}$ of $\mathbf{1}$ in $\mathrm{CH}_{3} \mathrm{CN}$ at room temperature with varying concentrations of $\mathrm{CH}_{3} \mathrm{CO}_{2} \mathrm{H}$. $\mathrm{I}_{\mathrm{o}}$ is the emission in the absence of $\mathrm{CH}_{3} \mathrm{CO}_{2} \mathrm{H}$. I is the corrected emission at a given concentration of $\mathrm{CH}_{3} \mathrm{CO}_{2} \mathrm{H}$. No appreciable quenching is observed. 


\section{Time-Resolved Photoluminescence Quenching}
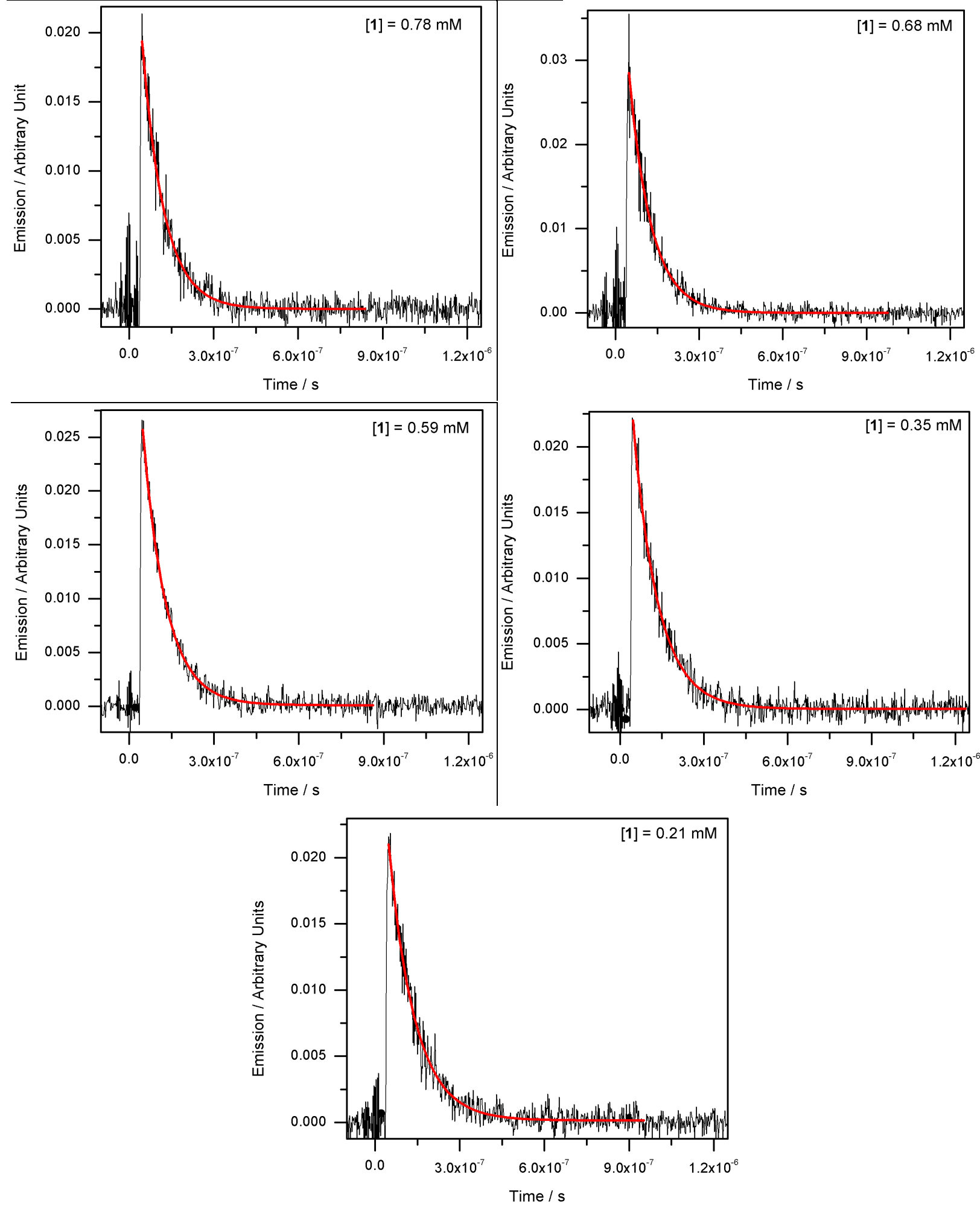

Figure S30. Time-resolved emission decay of 1 in $\mathrm{CH}_{3} \mathrm{CN}$ with $0.1 \mathrm{M}\left[\mathrm{Bu}_{4} \mathrm{~N}\right]\left[\mathrm{PF}_{6}\right]$ at room temperature at various concentrations of 1. Emission detected at $708 \mathrm{~nm}$. Excitation at $445 \mathrm{~nm}$. Emission of 1 measured at the following concentrations: $0.78,0.68,0.59,0.35,0.21 \mathrm{mM}$. Emission fit to a mono-exponential decay (red trace). Results of fits presented in Table S9. 
Table S9. Excited State Lifetimes of 1 in $\mathrm{CH}_{3} \mathrm{CN}$ with $0.1 \mathrm{M}\left[\mathrm{Bu}_{4} \mathrm{~N}\right]\left[\mathrm{PF}_{6}\right]$ at room temperature as determined by mono-exponential fitting of the emission decay. Emission detected at $708 \mathrm{~nm}$. Excitation at $445 \mathrm{~nm}$.

\begin{tabular}{|c|c|c|}
\hline$[\mathbf{1}] / \mathbf{m M}$ & $\boldsymbol{\tau} / \mathbf{n s}$ & $\mathbf{R}^{\mathbf{2}}$ \\
\hline 0.78 & 77.1 & 0.956 \\
\hline 0.68 & 79.3 & 0.958 \\
\hline 0.59 & 82.1 & 0.982 \\
\hline 0.35 & 89.6 & 0.967 \\
\hline 0.21 & 91.9 & 0.959 \\
\hline
\end{tabular}

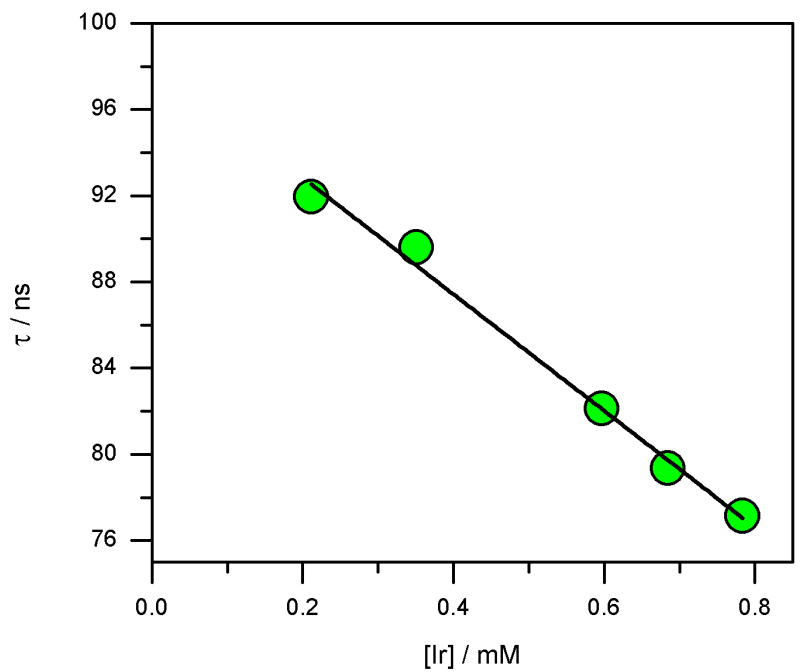

Figure S31. Plot of excited state lifetimes of 1 in $\mathrm{CH}_{3} \mathrm{CN}$ with $0.1 \mathrm{M}\left[\mathrm{Bu}_{4} \mathrm{~N}\right]\left[\mathrm{PF}_{6}\right]$ at room temperature at various concentrations of 1. Emission detected at $708 \mathrm{~nm}$. Excitation at $445 \mathrm{~nm}$. Linear fit of the data affords a lifetime at infinite dilution of 1 of $98.2 \mathrm{~ns}$.

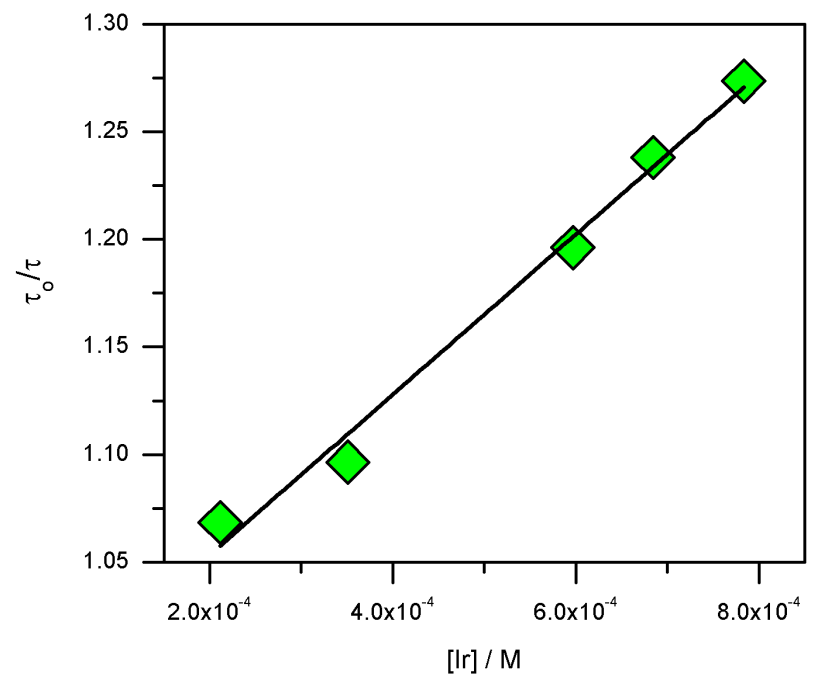

Figure S32. Stern-Volmer analysis of self-quenching of the excited state of $\mathbf{1}$ in $\mathrm{CH}_{3} \mathrm{CN}$ with $0.1 \mathrm{M}\left[\mathrm{Bu}_{4} \mathrm{~N}\right]\left[\mathrm{PF}_{6}\right]$. The intrinsic lifetime $\left(\tau_{\mathrm{o}}\right)$ taken to be $98.2 \mathrm{~ns}$. Linear fit affords a slope of 372.2 , resulting in a $\mathrm{K}_{\mathrm{SV}}$ of $370 \mathrm{M}^{-1}$ and a rate of quenching $\mathrm{k}_{\mathrm{q}}$ of $3.8 \times 10^{9} \mathrm{M}^{-1} \mathrm{~s}^{-1}$. 

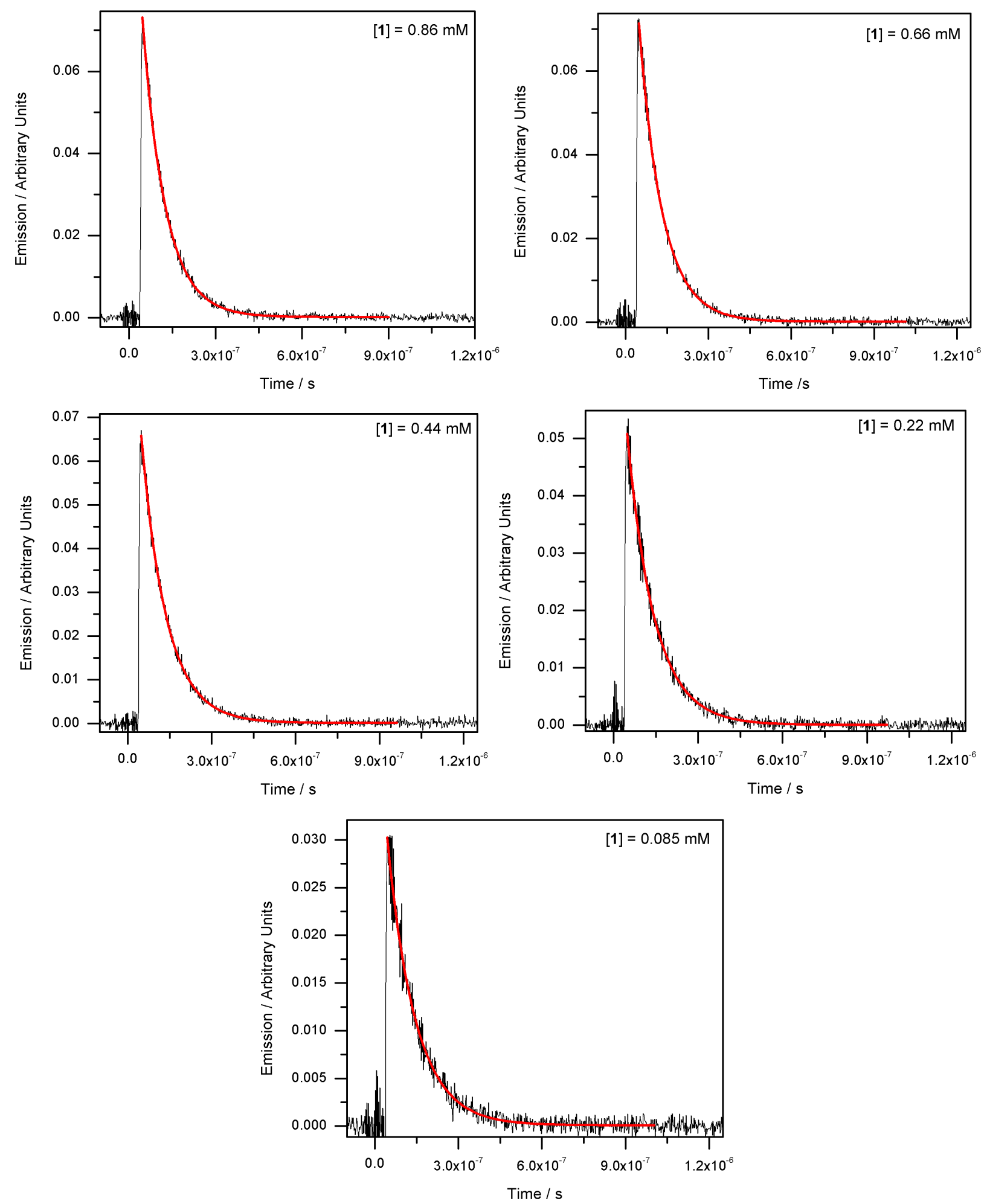

Figure S33. Time-resolved emission decay of 1 in $\mathrm{CH}_{3} \mathrm{CN}$ with $0.1 \mathrm{M}\left[\mathrm{Bu}_{4} \mathrm{~N}\right]\left[\mathrm{PF}_{6}\right]$ at room temperature at various concentrations of 1 in the presence of $50 \mathrm{mM} \mathrm{CH}_{3} \mathrm{CO}_{2} \mathrm{H}$. Emission detected at $708 \mathrm{~nm}$. Excitation at $445 \mathrm{~nm}$. Emission of 1 measured at the following concentrations: 0.86, 0.66, 0.44, 0.22, $0.085 \mathrm{mM}$. Emission fit to a mono-exponential decay (red trace). Results of fits presented in Table S10. 
Table S10. Excited State Lifetimes of 1 in $\mathrm{CH}_{3} \mathrm{CN}$ with $0.1 \mathrm{M}\left[\mathrm{Bu}_{4} \mathrm{~N}\right]\left[\mathrm{PF}_{6}\right]$ at room temperature in the presence of 50 $\mathrm{mM} \mathrm{CH} \mathrm{CO}_{2} \mathrm{H}$ as determined by mono-exponential fitting of the emission decay. Emission detected at $708 \mathrm{~nm}$. Excitation at $445 \mathrm{~nm}$.

\begin{tabular}{|c|c|c|}
\hline$[\mathbf{1}] / \mathbf{m} \mathbf{M}$ & $\boldsymbol{\tau} / \mathbf{n s}$ & $\mathbf{R}^{\mathbf{2}}$ \\
\hline 0.86 & 79.5 & 0.996 \\
\hline 0.66 & 84.5 & 0.997 \\
\hline 0.44 & 90.0 & 0.998 \\
\hline 0.22 & 96.7 & $0.97 \backslash 84$ \\
\hline 0.085 & 101.4 & 0.975 \\
\hline
\end{tabular}

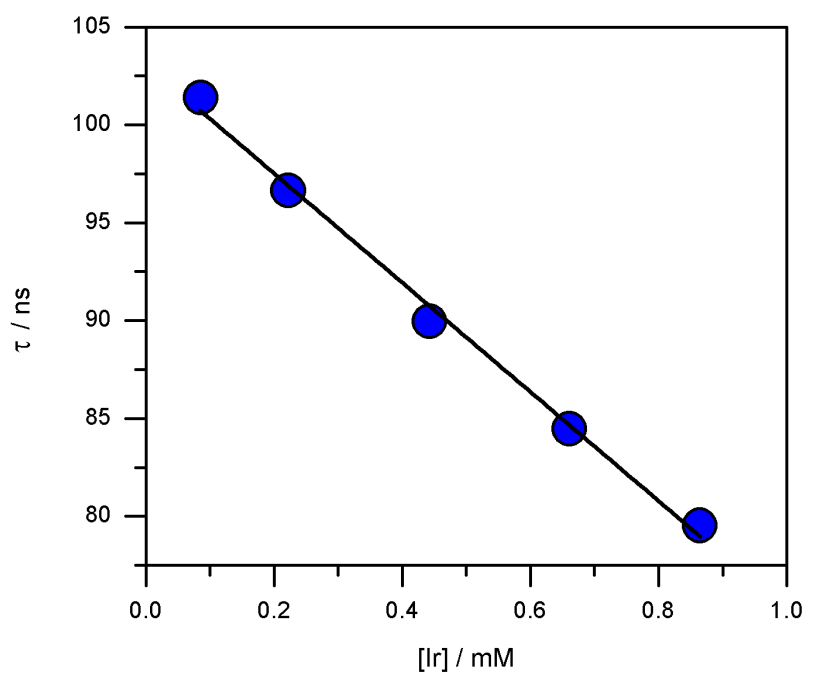

Figure S34. Plot of excited state lifetimes of 1 in $\mathrm{CH}_{3} \mathrm{CN}$ with $0.1 \mathrm{M}\left[\mathrm{Bu}_{4} \mathrm{~N}\right]\left[\mathrm{PF}_{6}\right]$ at room temperature at various concentrations of 1 in the presence of $50 \mathrm{mM} \mathrm{CH}_{3} \mathrm{CO}_{2} \mathrm{H}$. Emission detected at $708 \mathrm{~nm}$. Excitation at $445 \mathrm{~nm}$. Linear fit of the data affords a lifetime at infinite dilution of 1 of $103 \mathrm{~ns}$.

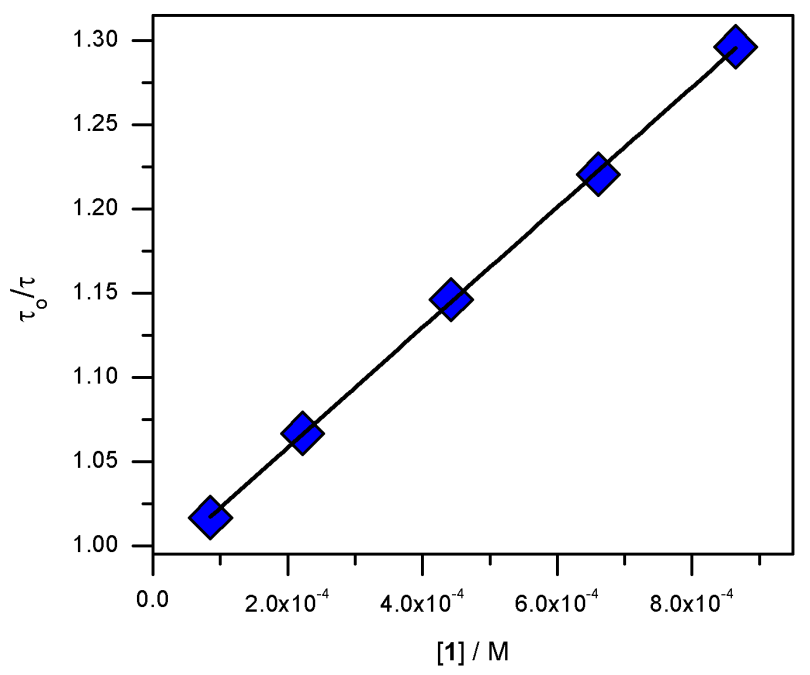

Figure S35. Stern-Volmer analysis of self-quenching of the excited state of $\mathbf{1}$ in $\mathrm{CH}_{3} \mathrm{CN}$ with $0.1 \mathrm{M}\left[\mathrm{Bu}_{4} \mathrm{~N}\right]\left[\mathrm{PF}_{6}\right]$ the presence of $50 \mathrm{mM} \mathrm{CH} \mathrm{CO}_{2} \mathrm{H}$. The intrinsic lifetime $\left(\tau_{\mathrm{o}}\right)$ taken to be $103 \mathrm{~ns}$. Linear fit affords a slope of 356.9, resulting in a $\mathrm{K}_{\mathrm{SV}}$ of $360 \mathrm{M}^{-1}$ and a rate of quenching $\mathrm{k}_{\mathrm{q}}$ of $3.5 \times 10^{9} \mathrm{M}^{-1} \mathrm{~s}^{-1}$. 

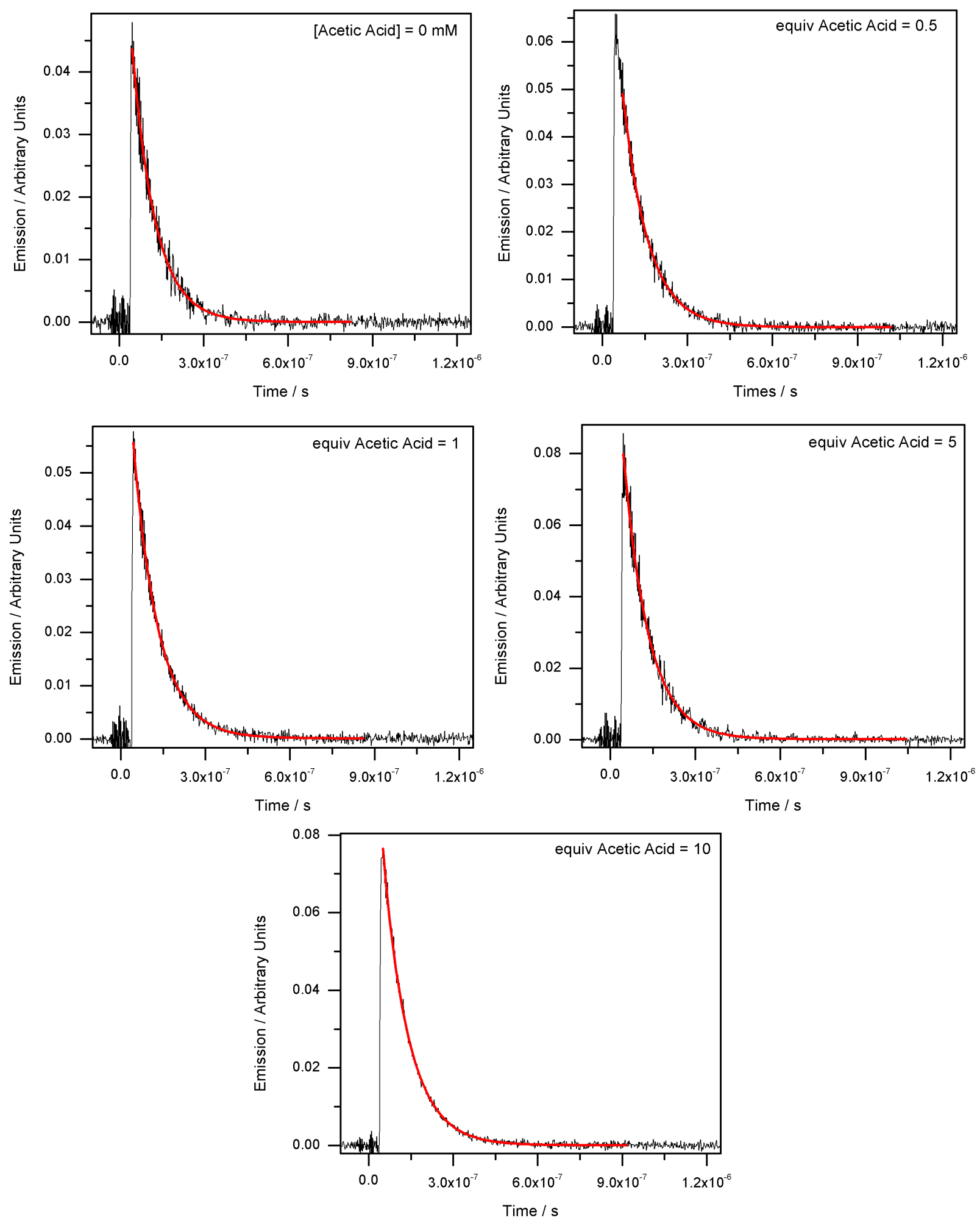

Figure S36. Time-resolved emission decay of $0.58 \mathrm{mM} 1$ in $\mathrm{CH}_{3} \mathrm{CN}$ with $0.1 \mathrm{M}\left[\mathrm{Bu}_{4} \mathrm{~N}\right]\left[\mathrm{PF}_{6}\right]$ at room temperature at various concentrations of $\mathrm{CH}_{3} \mathrm{CO}_{2} \mathrm{H}$. Emission detected at $708 \mathrm{~nm}$. Excitation at $445 \mathrm{~nm}$. Emission of 1 measured at the following concentrations of $\mathrm{CH}_{3} \mathrm{CO}_{2} \mathrm{H}: 0,0.29,0.58,2.9,5.8 \mathrm{mM}$. Emission fit to a mono-exponential decay (red trace). Results of fits presented in Table S11. 
Table S11. Excited State Lifetimes of $0.58 \mathrm{mM} 1$ in $\mathrm{CH}_{3} \mathrm{CN}$ with $0.1 \mathrm{M}\left[\mathrm{Bu}_{4} \mathrm{~N}\right]\left[\mathrm{PF}_{6}\right]$ at room temperature at various concentrations of $\mathrm{CH}_{3} \mathrm{CO}_{2} \mathrm{H}$ as determined by mono-exponential fitting of the emission decay. Emission detected at $708 \mathrm{~nm}$. Excitation at $445 \mathrm{~nm}$.

\begin{tabular}{|c|c|c|c|}
\hline$[\mathbf{1}] / \mathbf{m M}$ & {$\left[\mathbf{C H}_{\mathbf{3}} \mathbf{C O}_{\mathbf{2}} \mathbf{H}\right] / \mathbf{m M}$} & $\boldsymbol{\tau} / \mathbf{n s}$ & $\mathbf{R}^{\mathbf{2}}$ \\
\hline 0.58 & 0 & 81.8 & 0.975 \\
\hline 0.58 & 0.29 & 89.2 & 0.985 \\
\hline 0.58 & 0.58 & 88.8 & 0.989 \\
\hline 0.58 & 2.9 & 88.4 & 0.992 \\
\hline 0.58 & 5.8 & 90.4 & 0.996 \\
\hline
\end{tabular}

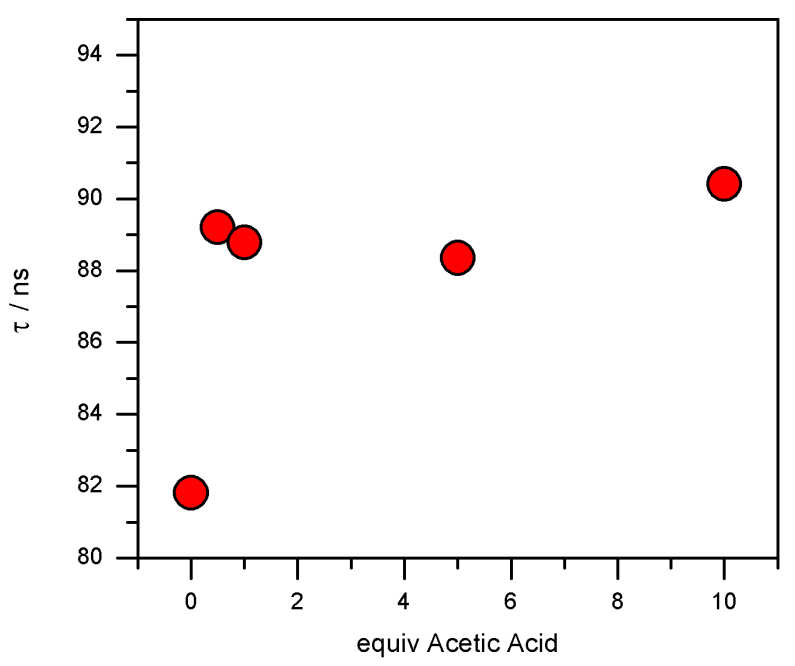

Figure S37. Plot of excited state lifetimes of $0.58 \mathrm{mM} 1$ in $\mathrm{CH}_{3} \mathrm{CN}$ with $0.1 \mathrm{M}\left[\mathrm{Bu}_{4} \mathrm{~N}\right]\left[\mathrm{PF}_{6}\right]$ at room temperature at various concentrations of $\mathrm{CH}_{3} \mathrm{CO}_{2} \mathrm{H}$. Emission detected at $708 \mathrm{~nm}$. Excitation at $445 \mathrm{~nm}$. The lifetime increased slightly with the initial addition of acid, but further increasing the acid concentration did not result in any appreciable variation in lifetime. 

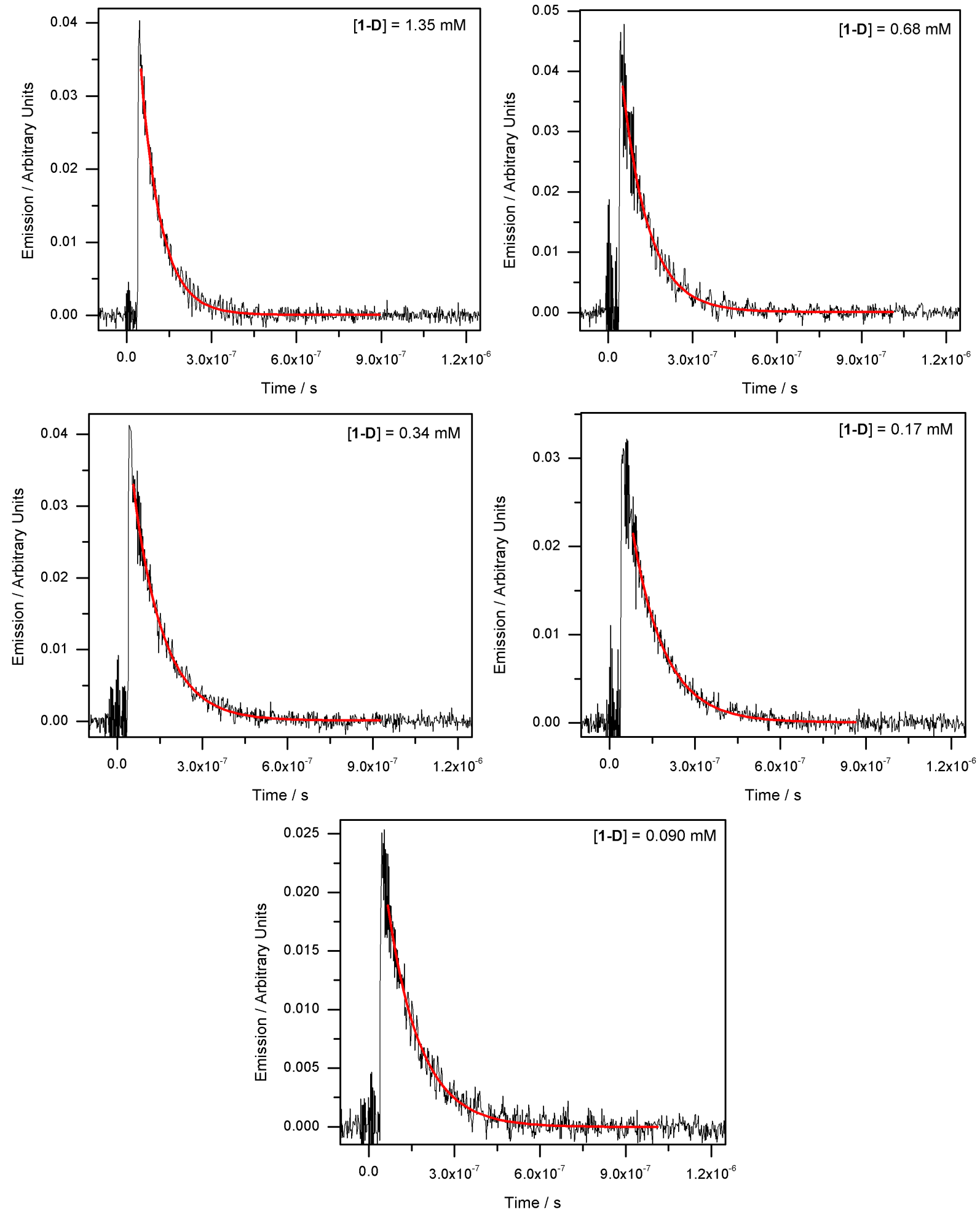

Figure S38. Time-resolved emission decay of 1-D in $\mathrm{CH}_{3} \mathrm{CN}$ with $0.1 \mathrm{M}\left[\mathrm{Bu}_{4} \mathrm{~N}\right]\left[\mathrm{PF}_{6}\right]$ at room temperature at various concentrations of 1-D. Emission detected at $708 \mathrm{~nm}$. Excitation at $445 \mathrm{~nm}$. Emission of 1 measured at the following concentrations: $1.35,0.68,0.34,0.17,0.090 \mathrm{mM}$. Emission fit to a mono-exponential decay (red trace). Results of fits presented in Table S12. 
Table S12. Excited State Lifetimes of 1-D in $\mathrm{CH}_{3} \mathrm{CN}$ with $0.1 \mathrm{M}\left[\mathrm{Bu}_{4} \mathrm{~N}\right]\left[\mathrm{PF}_{6}\right]$ at room temperature as determined by mono-exponential fitting of the emission decay. Emission detected at $708 \mathrm{~nm}$. Excitation at $445 \mathrm{~nm}$.

\begin{tabular}{|c|c|c|}
\hline$[\mathbf{1}-\mathbf{D}] / \mathbf{m M}$ & $\boldsymbol{\tau} / \mathbf{n s}$ & $\mathbf{R}^{\mathbf{2}}$ \\
\hline 1.35 & 73.1 & 0.996 \\
\hline 0.68 & 93.1 & 0.997 \\
\hline 0.34 & 104.8 & 0.998 \\
\hline 0.17 & 113.9 & 0.978 \\
\hline 0.090 & 114.8 & 0.975 \\
\hline
\end{tabular}

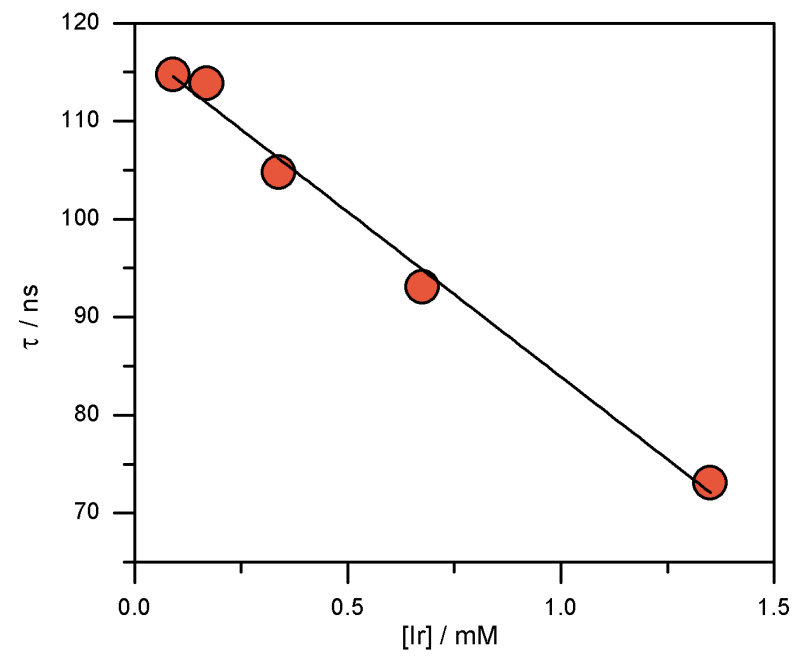

Figure S39. Plot of excited state lifetimes of 1-D in $\mathrm{CH}_{3} \mathrm{CN}$ with $0.1 \mathrm{M}\left[\mathrm{Bu}_{4} \mathrm{~N}\right]\left[\mathrm{PF}_{6}\right]$ at room temperature at various concentrations of 1-D. Emission detected at $708 \mathrm{~nm}$. Excitation at $445 \mathrm{~nm}$. Linear fit of the data affords a lifetime at infinite dilution of 1-D of $117.6 \mathrm{~ns}$.

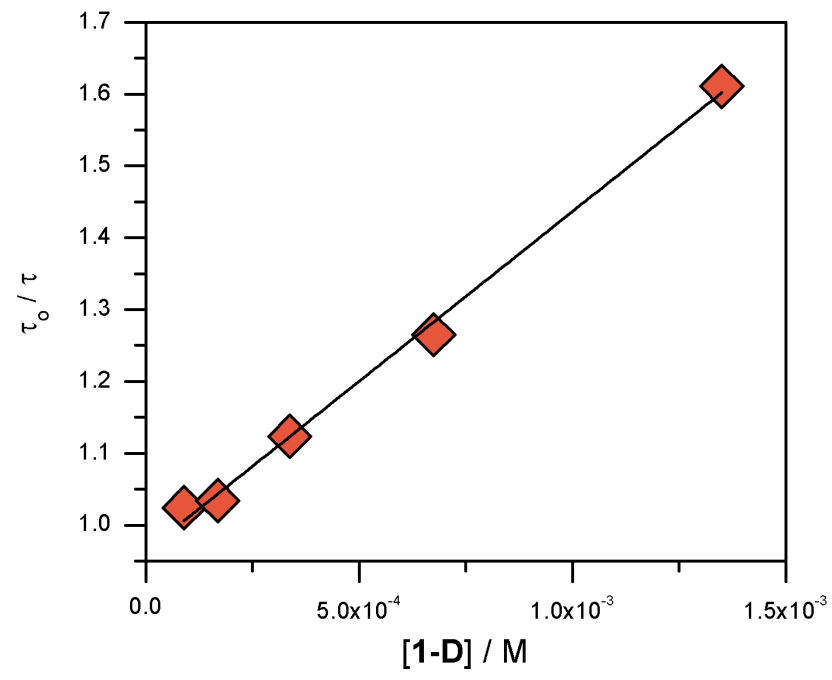

Figure S40. Stern-Volmer analysis of self-quenching of the excited state of 1-D. The intrinsic lifetime $\left(\tau_{\mathrm{o}}\right)$ taken to be $117.6 \mathrm{~ns}$. Linear fit affords a slope of 472.7 , resulting in a $\mathrm{K}_{\mathrm{SV}}$ of $470 \mathrm{M}^{-1}$ and a rate of quenching $\mathrm{k}_{\mathrm{q}}$ of $4.0 \times 10^{9}$ $\mathrm{M}^{-1} \mathrm{~s}^{-1}$ 

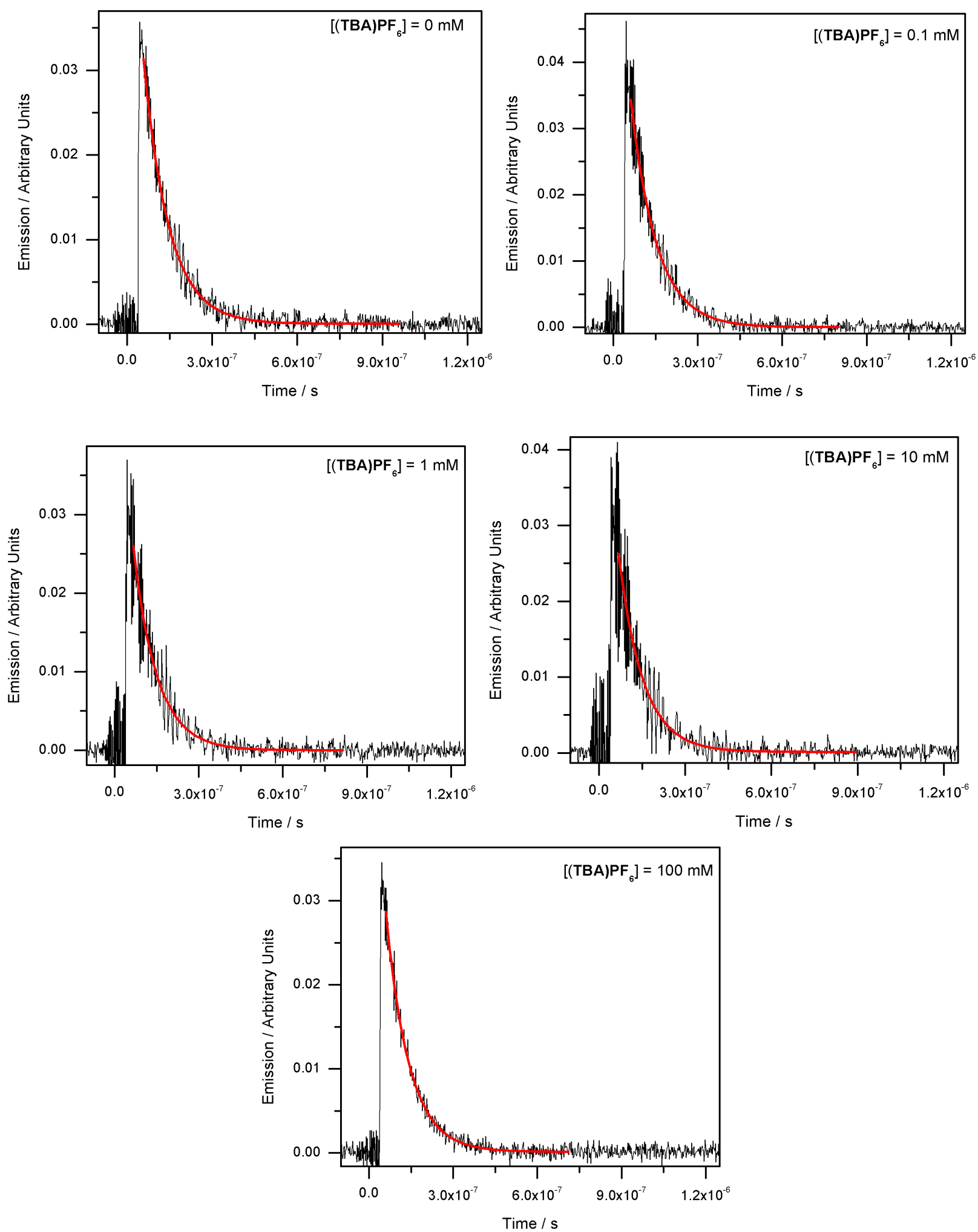

Figure S41. Time-resolved emission decay of $0.55 \mathrm{mM} 1$ in $\mathrm{CH}_{3} \mathrm{CN}$ with $50 \mathrm{mM} \mathrm{CH}_{3} \mathrm{CO}_{2} \mathrm{H}$ at room temperature at various concentrations of $\left[\mathrm{Bu}_{4} \mathrm{~N}\right]\left[\mathrm{PF}_{6}\right]$. Emission detected at $708 \mathrm{~nm}$. Excitation at $445 \mathrm{~nm}$. Emission of 1 measured at the following concentrations of $\left[\mathrm{Bu}_{4} \mathrm{~N}\right]\left[\mathrm{PF}_{6}\right]: 0,0.1,1,10,100 \mathrm{mM}$. Emission fit to a mono-exponential decay (red trace). Results of fits presented in Table S13. 
Table S13. Excited State Lifetimes of $0.55 \mathrm{mM} 1$ in $\mathrm{CH}_{3} \mathrm{CN}$ with $50 \mathrm{mM} \mathrm{CH}_{3} \mathrm{CO}_{2} \mathrm{H}$ at room temperature at various concentrations of $\left[\mathrm{Bu}_{4} \mathrm{~N}\right]\left[\mathrm{PF}_{6}\right]$ as determined by mono-exponential fitting of the emission decay. Emission detected at $708 \mathrm{~nm}$. Excitation at $445 \mathrm{~nm}$.

\begin{tabular}{|c|c|c|}
\hline$\left[\left(\mathbf{B u}_{\mathbf{4}} \mathbf{N}\right) \mathbf{P F}_{\mathbf{6}}\right] / \mathbf{m} \mathbf{M}$ & $\tau / \mathbf{n s}$ & $\mathbf{R}^{\mathbf{2}}$ \\
\hline 0 & 88.6 & 0.959 \\
\hline 0.1 & 89.6 & 0.946 \\
\hline 1 & 86.7 & 0.900 \\
\hline 10 & 84.1 & 0.856 \\
\hline 100 & 82.5 & 0.983 \\
\hline
\end{tabular}

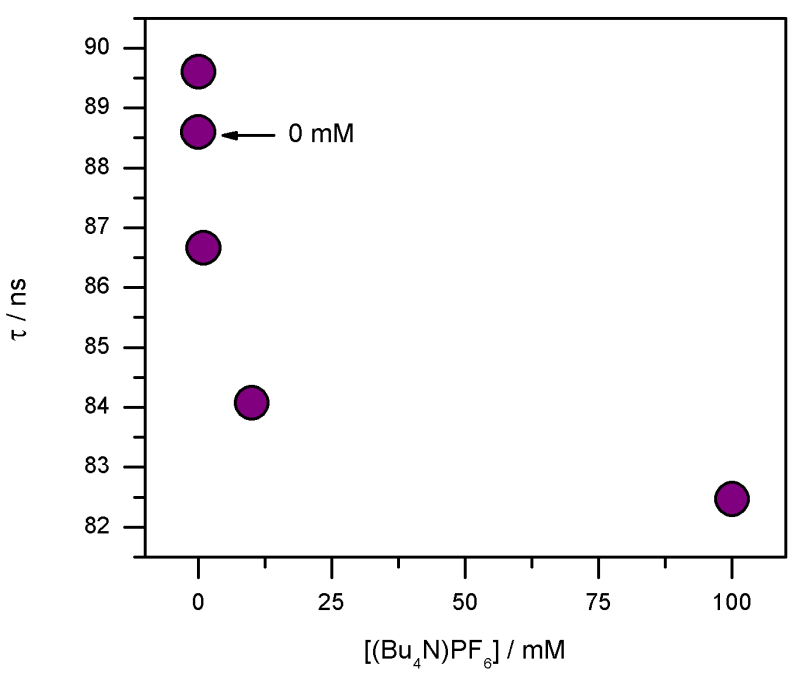

Figure S42. Plot of excited state lifetimes of 1 in $\mathrm{CH}_{3} \mathrm{CN}$ with $50 \mathrm{mM} \mathrm{CH}_{3} \mathrm{CO}_{2} \mathrm{H}$ at room temperature at various concentrations of $\left[\mathrm{Bu}_{4} \mathrm{~N}\right]\left[\mathrm{PF}_{6}\right]$. Emission detected at $708 \mathrm{~nm}$. Excitation at $445 \mathrm{~nm}$. Increasing amounts of electrolyte correlate to decreased lifetimes of the excited state of $\mathbf{1}$. 


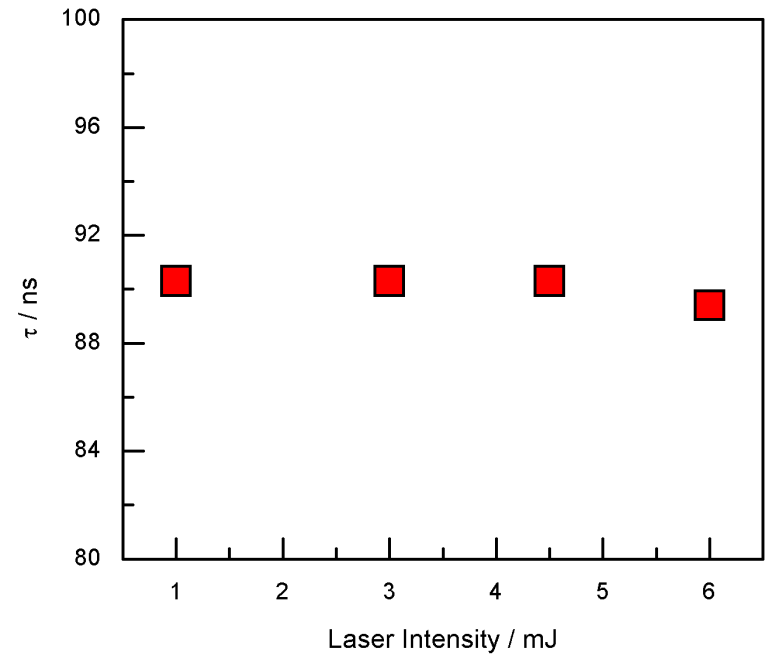

Figure S43. Plot of excited state lifetimes of $0.42 \mathrm{mM} 1$ in $\mathrm{CH}_{3} \mathrm{CN}$ with $50 \mathrm{mM} \mathrm{CH}_{3} \mathrm{CO}_{2} \mathrm{H}$ and $0.1 \mathrm{M}\left[\mathrm{Bu}_{4} \mathrm{~N}\right]\left[\mathrm{PF}_{6}\right]$. Emission detected at $708 \mathrm{~nm}$. Excitation at $445 \mathrm{~nm}$ with varying excitation laser power. No significant variation is observed 


\section{$\underline{\text { IX. Electrochemical Results }}$}

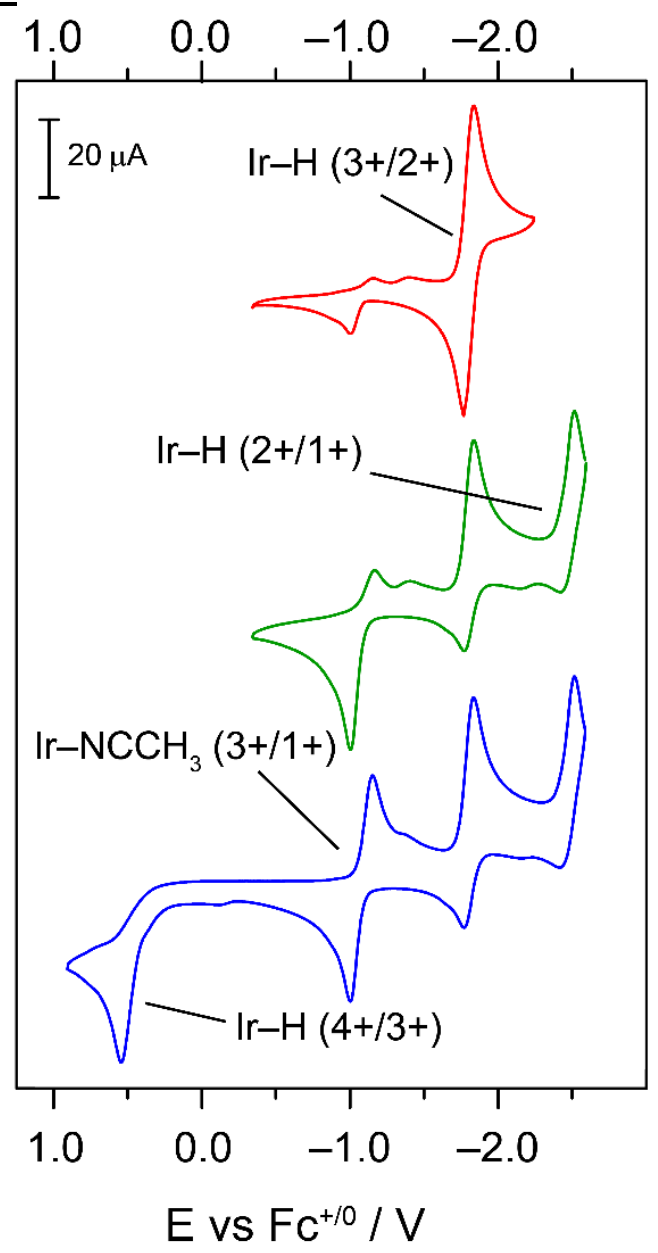

Figure S44. Cyclic voltammograms of $1 \mathrm{mM} 1$ in $\mathrm{CH}_{3} \mathrm{CN}$ with $0.2 \mathrm{M}\left[\mathrm{Bu}_{4} \mathrm{~N}\right]\left[\mathrm{PF}_{6}\right]$ under an atmosphere of $\mathrm{N}_{2}$. Scan rate $0.1 \mathrm{~V} / \mathrm{s}$, glassy carbon working electrode, platinum wire counter electrode, $\mathrm{Ag} / \mathrm{Ag}^{+}$pseudo reference electrode. Data collected with a WaveNow potentiostat from Pine Instruments that was pumped into the glovebox and connected to an external computer via a custom USB feedthrough. 

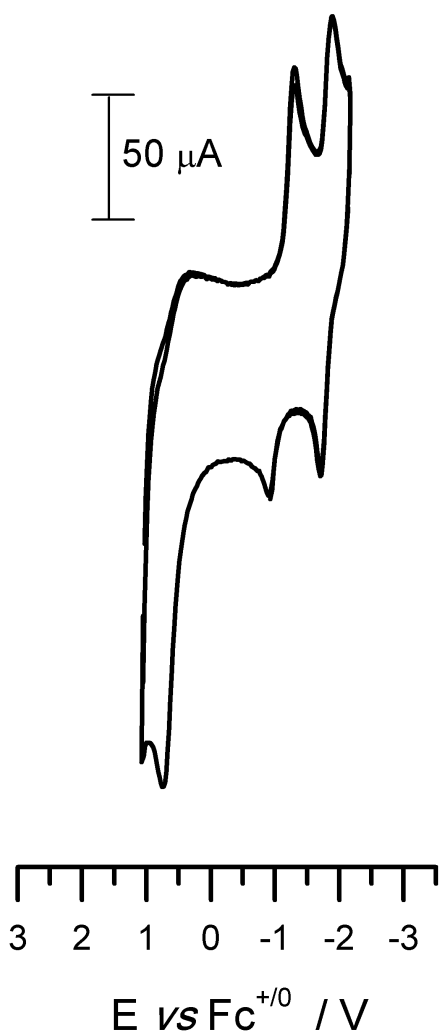

Figure S45. Cyclic voltammogram of $1 \mathrm{mM} 1$ in $\mathrm{CH}_{3} \mathrm{CN}$ with $0.200 \mathrm{M}\left[\mathrm{Bu}_{4} \mathrm{~N}\right]\left[\mathrm{PF}_{6}\right]$ under an atmosphere of $\mathrm{N}_{2}$. Scan rate $200 \mathrm{~V} / \mathrm{s}$, glassy carbon working electrode, platinum wire counter electrode, $\mathrm{Ag} / \mathrm{Ag}^{+}$pseudo reference electrode. Data collected with a WaveDriver potentiostat from Pine Instruments that was kept external to the glovebox, and the electrode leads were connected with a custom shielded electrode cable feedthrough. 


\section{$\underline{X}$. Thermochemical Evaluation of $1 *$ Reactivity Pathways}

\section{Experimental thermochemical data}

$E^{\mathrm{o}}\left([\operatorname{IrH}]^{+} /[\mathrm{IrH}]^{0}\right)=-1.80 \mathrm{~V}$ vs Fc $\quad \Delta G^{\mathrm{o}}=41.51 \mathrm{kcal} / \mathrm{mol}$

$E^{\mathrm{o}}\left([\operatorname{IrH}]^{2+} /[\mathrm{IrH}]^{+}\right)=+0.50 \mathrm{~V}$ vs. Fc $\quad \Delta G^{\mathrm{o}}=-11.53 \mathrm{kcal} / \mathrm{mol}$

$E^{\mathrm{o}}\left([\mathrm{Ir}-\mathrm{NCMe}]^{2+} /[\mathrm{Ir}]^{0}\right)=-1.07 \mathrm{~V}$ vs. Fc $\quad \Delta G^{\mathrm{o}}=49.35 \mathrm{kcal} / \mathrm{mol}$

$\mathrm{p} K_{\mathrm{a}}\left([\mathrm{IrH}]^{+}\right)=23.3 \quad \Delta G^{\mathrm{o}}=31.78 \mathrm{kcal} / \mathrm{mol}$

$\Delta G_{\mathrm{ST}}^{\mathrm{o}}=E^{00}=47-52 \mathrm{kcal} / \mathrm{mol}=50(2) \mathrm{kcal} / \mathrm{mol}$

Scheme S1. Ground State Thermochemical Overview

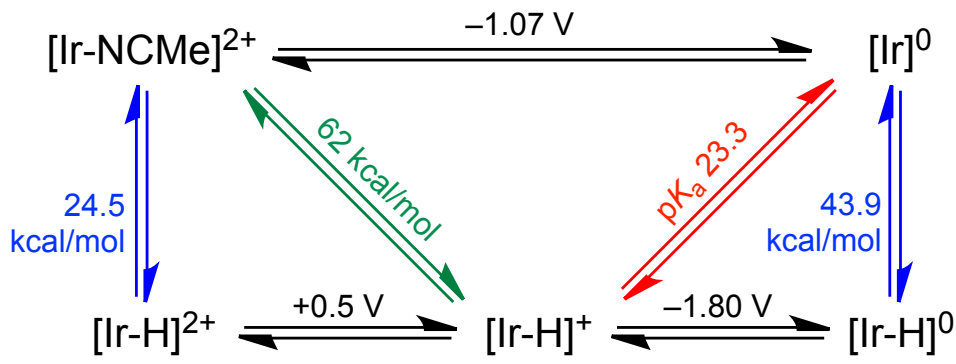

Scheme S2. Excited state reduction potentials

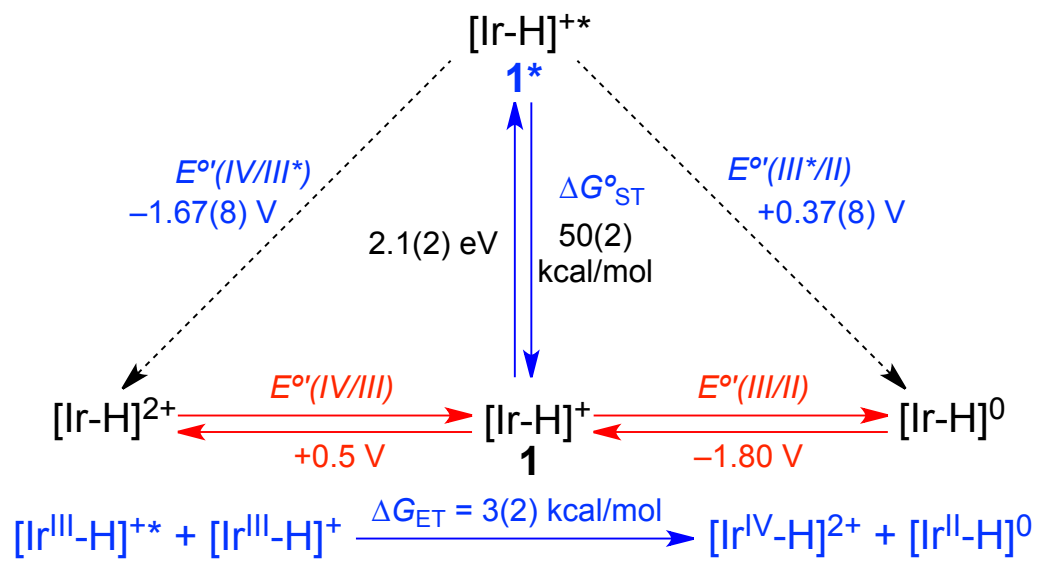




$$
\begin{array}{ll}
{[\mathrm{IrH}]^{2+}+\mathrm{e}^{-} \rightarrow \mathbf{1}} & \Delta G^{\mathrm{o}}=-(1)(23.06)(0.5)=-11.53 \mathrm{kcal} / \mathrm{mol} \\
\mathbf{1} \rightarrow \mathbf{1} & -\Delta G_{\mathrm{ST}}^{\mathrm{o}}=+50 \mathrm{kcal} / \mathrm{mol} \\
\hline[\mathrm{IrH}]^{2+}+\mathrm{e}^{-} \rightarrow \mathbf{1} * & \Delta G^{\mathbf{o}}=+38.47 \mathrm{kcal} / \mathrm{mol} \\
& \boldsymbol{E}^{\mathbf{0} *}=-\mathbf{1 . 6 7}(\mathbf{8}) \mathbf{V} \\
& \\
\mathbf{1 *} \rightarrow \mathbf{1} & \Delta G_{\mathrm{ST}}^{\mathrm{o}}=-50 \mathrm{kcal} / \mathrm{mol} \\
\mathbf{1}+\mathrm{e}^{-} \rightarrow[\mathrm{IrH}]^{0} & \Delta G^{\mathbf{o}}=-(1)(23.06)(-1.80)=+41.51 \mathrm{kcal} / \mathrm{mol} \\
\hline \mathbf{1 *}+\mathrm{e}^{-} \rightarrow[\mathrm{IrH}]^{0} & \Delta G^{\mathbf{o}}=-8.49 \mathrm{kcal} / \mathrm{mol} \\
& \boldsymbol{E}^{\mathbf{0} *}=+\mathbf{0 . 3 7}(\mathbf{8}) \mathbf{V}
\end{array}
$$

Free energy of self-quenching reaction

$$
\begin{array}{ll}
\mathbf{1} \rightarrow \mathbf{1} & -\Delta G_{\mathrm{ST}}=-50 \mathrm{kcal} / \mathrm{mol} \\
\mathbf{1}+\mathrm{e}^{-} \rightarrow[\mathrm{IrH}]^{0} & \Delta G^{\mathrm{o}}=-23.06(-1.80)=41.51 \mathrm{kcal} / \mathrm{mol} \\
\mathbf{1} \rightarrow[\operatorname{IrH}]^{2+}+\mathrm{e}^{-} & \Delta G^{\mathrm{o}}=23.06(0.5)=11.53 \mathrm{kcal} / \mathrm{mol} \\
\hline \mathbf{1}^{*}+\mathbf{1} \rightarrow[\operatorname{IrH}]^{0}+[\operatorname{IrH}]^{2+} & \Delta G_{\mathrm{ET}}^{\mathrm{o}}=+3(2) \mathrm{kcal} / \mathrm{mol}
\end{array}
$$

\section{Bond Dissociation Free Energy Calculations}

\begin{tabular}{ll}
{$[\mathrm{IrH}]^{0} \rightarrow \mathbf{1}+\mathrm{e}^{-}$} & $\Delta G^{\mathrm{o}}=(1)(23.06)(-1.80)=-41.51 \mathrm{kcal} / \mathrm{mol}$ \\
$\mathbf{1} \rightarrow \mathbf{3}+\mathrm{H}^{+}$ & $\Delta G^{\mathrm{o}}=1.364(23.3)=31.78 \mathrm{kcal} / \mathrm{mol}$ \\
$\mathrm{H}^{+}+\mathrm{e}^{-} \rightarrow \mathrm{H}^{\bullet}$ & $\Delta G^{\mathrm{o}}=53.6 \mathrm{kcal} / \mathrm{mol}$ \\
\hline$[\mathrm{IrH}]^{0} \rightarrow \mathbf{3}+\mathrm{H}^{\cdot}$ & $\Delta G^{\mathrm{o}}{ }_{\mathrm{BDFE}}=43.9 \mathrm{kcal} / \mathrm{mol}$ \\
{$[\mathrm{IrH}]^{2+}+\mathrm{e}^{-} \rightarrow \mathbf{1}$} & $\Delta G^{\mathrm{o}}=-(1)(23.06)(0.50)=-11.53 \mathrm{kcal} / \mathrm{mol}$ \\
$\mathbf{1}+\mathrm{MeCN}^{\rightarrow} \mathbf{2 - M e C N}+\mathrm{H}^{-}$ & $\Delta G^{\mathrm{o}}=62.0 \mathrm{kcal} / \mathrm{mol}$ \\
$\mathrm{H}^{-} \rightarrow \mathrm{e}^{-}+\mathrm{H}^{\bullet}$ & $\Delta G^{\mathrm{o}}=-26.0 \mathrm{kcal} / \mathrm{mol}$ \\
\hline$[\mathrm{IrH}]^{2+}+\mathrm{MeCN} \rightarrow \mathbf{2 - M e C N}+\mathrm{H}^{\cdot}$ & $\Delta G^{\mathrm{o}}{ }_{\mathrm{BDFE}}=24.5 \mathrm{kcal} / \mathrm{mol}$
\end{tabular}


Free energy of $\mathrm{H}_{2}$ release reaction

\begin{tabular}{ll}
{$[\mathrm{IrH}]^{0} \rightarrow \mathbf{3}+\mathrm{H} \bullet$} & $\Delta G^{\mathrm{o}}=43.9 \mathrm{kcal} / \mathrm{mol}$ \\
{$[\mathrm{IrH}]^{2+}+\mathrm{MeCN} \rightarrow$ 2-MeCN $+\mathrm{H} \bullet$} & $\Delta G^{\mathbf{o}}=24.5 \mathrm{kcal} / \mathrm{mol}$ \\
$2 \mathrm{H} \bullet \rightarrow \mathrm{H}_{2}$ & $\Delta G^{\mathrm{o}}=-103.6 \mathrm{kcal} / \mathrm{mol}$ \\
\hline$[\mathrm{IrH}]^{0}+[\mathrm{IrH}]^{2+}+\mathrm{MeCN} \rightarrow \quad \mathbf{3}+\mathbf{2 - M e C N}+\mathrm{H}_{2}$ & $\Delta G^{\mathrm{o}} \mathrm{H} 2=-35.2 \mathrm{kcal} / \mathrm{mol}$
\end{tabular}

Scheme S3. Qualitative Free Energy Landscape

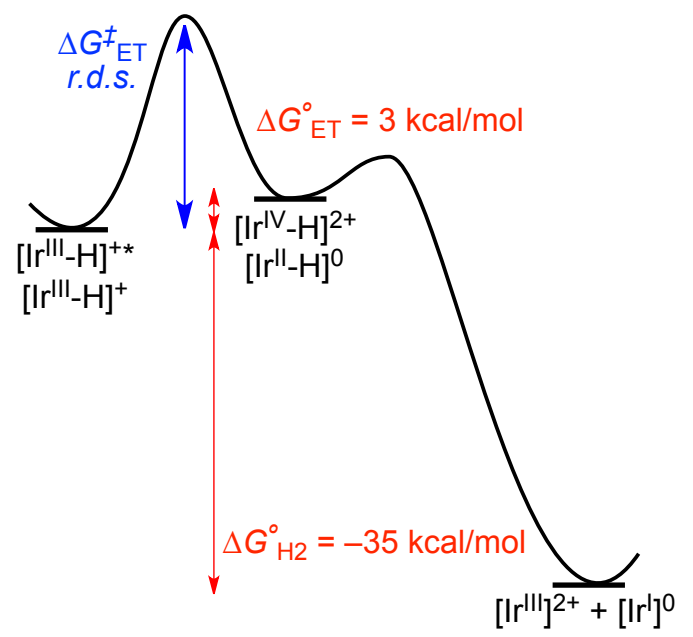

$\mathrm{H}_{2}$ 


\section{References}

(1) White, C.; Yates, A.; Maitlis, P. M. Inorg. Synth. 1992, 29, 228.

(2) Pitman, C. L.; Brereton, K. R.; Miller, A. J. M. J. Am. Chem. Soc. 2016, 138, 2252.

(3) McCarthy, B. D.; Martin, D. J.; Rountree, E. S.; Ullman, A. C.; Dempsey, J. L. Inorg. Chem. 2014, $53,8350$.

(4) Lennon, P.; Rosenblum, M. J. Am. Chem. Soc. 1983, 105, 1233.

(5) Turro, N. J.; Chen, J. Y. C.; Sartori, E.; Ruzzi, M.; Marti, A.; Lawler, R.; Jockusch, S.; López-Gejo, J.; Komatsu, K.; Murata, Y. Acc. Chem. Res. 2010, 43, 335.

(6) Pitman, C. L.; Miller, A. J. M. ACS Catal. 2014, 4, 2727.

(7) Smith, T. J.; Stevenson, K. J. Handbook of Electrochemistry; Zoski, C. G., Ed.; Elsevier: Amsterdam, 2007; Vol. 53.

(8) Delahay, P.; Stiehl, G. L. J. Am. Chem. Soc. 1952, 74, 3500.

(9) Parker, C. A.; Rees, W. T. Analyst 1960, 85, 587.

(10) Kestell, J. D.; Williams, Z. L.; Stultz, L. K.; Claude, J. P. J. Phys. Chem. A 2002, 106, 5768.

(11) Kober, E. M.; Caspar, J. V.; Lumpkin, R. S.; Meyer, T. J. J. Phys. Chem. 1986, 90, 3722.

(12) Claude, J. P.; Meyer, T. J. J. Phys. Chem. 1995, 99, 51.

(13) Ito, A.; Meyer, T. J. Phys. Chem. Chem. Phys 2012, 14, 13731.

(14) Barrett, S. M.; Pitman, C. L.; Walden, A. G.; Miller, A. J. M. J. Am. Chem. Soc. 2014, $136,14718$.

(15) Abura, T.; Ogo, S.; Watanabe, Y.; Fukuzumi, S. J. Am. Chem. Soc. 2003, 125, 4149.

(16) Montalti, M.; Credi, A.; Prodi, L.; MT, G. Handbook of Photochemistry, 3rd ed.; CRC Press: Boca Raton, 2006.

(17) Kubista, M.; Sjoeback, R.; Eriksson, S.; Albinsson, B. Analyst 1994, 119, 417. 